\title{
Ultraclean Layers and Optically Thin Clouds in the Stratocumulus-to-Cumulus Transition. Part II: Depletion of Cloud Droplets and Cloud Condensation Nuclei through Collision-Coalescence
}

\author{
KuAN-Ting O, Robert WoOd, AND CHRistopher S. BRETHERTON \\ Department of Atmospheric Sciences, University of Washington, Seattle, Washington
}

(Manuscript received 28 July 2017, in final form 18 February 2018)

\begin{abstract}
In Part I, aircraft observations are used to show that ultraclean layers (UCLs) in the marine boundary layer (MBL) are a common feature of the stratocumulus-to-cumulus transition (SCT) region over the northeast Pacific. The ultraclean layers are defined as layers of either cloud or clear air in which the concentration of particles with diameter larger than $0.1 \mu \mathrm{m}$ is below $10 \mathrm{~cm}^{-3}$. Here, idealized microphysical parcel modeling shows that in the cumulus regime, collision-coalescence can strongly deplete cloud droplet concentration in cumulus $(\mathrm{Cu})$ updrafts, thereby removing cloud condensation nuclei $(\mathrm{CCN})$ from the atmosphere, suggesting that collision scavenging is likely the key process causing the low particle concentration in UCLs. Furthermore, the model results suggest that the stratocumulus regime is typically not favorable for UCL formation, because condensate amounts are generally not large enough to deplete drops in the time it takes to loft air to the upper planetary boundary layer (PBL). A bulk parameterization of the coalescence-scavenging rate is derived based on in situ measurements. The fractional coalescence-scavenging rate is found to be strongly dependent upon liquid water content (LWC) and, hence, the height above cloud base, indicating that a higher cloud top and thus a greater cloud thickness in a $\mathrm{Cu}$ updraft is an important factor accounting for the observed sharp rise of UCL coverage in the SCT region. An important implication is that PBL height, which controls maximum cloud thickness, and therefore LWC in updrafts, could be a crucial factor constraining coalescence scavenging and thus the formation of UCLs in the MBL.
\end{abstract}

\section{Introduction}

The number concentration of water droplets $N_{d}$ and cloud condensation nuclei $(\mathrm{CCN}) N_{\text {ccn }}$ continue to be variables of importance in marine boundary layer (MBL) clouds because they help determine cloud albedo (i.e., first indirect effect; Twomey 1977) and its perturbation due to aerosol can modulate the ability to form precipitation (Albrecht 1989). The $N_{d}$ is limited by $N_{\text {ccn }}$ through the process of cloud droplet activation in which CCN serve as nuclei for cloud droplets. Changes in precipitation due to variations in $N_{d}$ and $N_{\text {ccn }}$ can enhance the change in cloud albedo associated with the Twomey effect. The smaller droplet size (i.e., smaller effective radius $r_{e}$ ) resulting from increasing $N_{d}$ and $N_{\text {ccn }}$ (for a given cloud liquid water content $q_{L}$ ) can hinder collision-coalescence and result in a lower precipitation rate at cloud base $R_{\mathrm{cb}}$, which could potentially increase cloud lifetime and hence cloud albedo, often called the

\footnotetext{
Corresponding author: Kuan-Ting O, ktoandy@uw.edu
}

second indirect effect (Albrecht 1989). Several observational studies have found a consistent relationship between $R_{\mathrm{cb}}$ and $N_{d}$ in MBL clouds and suggest that $R_{\mathrm{cb}}$ generally decreases as $N_{d}$ increases (Hudson and $\mathrm{Li}$ 1995; Ferek et al. 2000; Bretherton et al. 2004; Wood 2005; Lu et al. 2007; Terai et al. 2012). However, there remain discrepancies in the degree of precipitation susceptibility to $N_{d}$ and its dependence on liquid water path (LWP) and cloud thickness $H_{t}$ across modeling and observational studies (Feingold and Siebert 2009; Sorooshian et al. 2009; Terai et al. 2015; Jung et al. 2016). Several studies have suggested that the changes in macrophysical processes such as entrainment rate in the MBL induced by aerosol perturbations can counter the second indirect effect and, in some cases, may overcome it (Ackerman et al. 2004; Wood 2007; Bretherton et al. 2007; Small et al. 2009; Lee et al. 2012), emphasizing the difficulty in establishing a simple susceptibility metric.

Previous studies have focused upon variability of $N_{d}$ and $N_{\text {ccn }}$ as a driver of variability in precipitation. On the other hand, precipitation can also act as the driver of 
variability in $N_{d}$ and $N_{\text {ccn }}$ through collision-coalescence. As pointed out by Hudson and Frisbie (1991), collisioncoalescence can efficiently remove $\mathrm{CCN}$ within droplets from the atmosphere even with light precipitation rate (Feingold et al. 1996; Wood 2006). An evaporated coalesced droplet only leaves behind one residual haze particle that is made up of the nuclei from many droplets, the so-called coalescence-scavenging process, which is an irreversible process. Recently, by using a simplified aerosol budget model, driven by observations from aircraft and satellites, Wood et al. (2012) showed that the geographical and temporal variability of global MBL $N_{d}$ and $N_{\text {ccn }}$ are highly impacted by coalescence scavenging. This poses a potential positive feedback in the aerosol-cloud-precipitation interaction as suggested by recent modeling studies (Yang et al. 2012; Berner et al. 2013) such that the increase in $N_{\text {ccn }}$ can reduce the efficiency of precipitation sink of $N_{\text {ccn }}$, which hence amplify the initial perturbation of increasing $N_{\mathrm{ccn}}$.

In situ measurements showing the coalescencescavenging driving of the vertical variability in $N_{d}$ and $N_{\text {ccn }}$ have been presented in a mounting body of previous studies. Early in situ measurements of marine cumulus have reported that there is a substantial decrease in $N_{d}$ with increasing height (Weickmann and Aufm Kampe 1953; Squires 1958), suggesting the efficient depletion of $N_{d}$ by collision-coalescence. Measurements of $N_{\text {ccn }}$ in cumulus and stratocumulus decks over the northeastern Pacific Ocean (Hudson and Frisbie 1991; Hudson 1993) have shown there is vertical decrease of $N_{\mathrm{ccn}}$, which the authors attributed to coalescence scavenging. Aircraft observations of MBL clouds over the southern Pacific Ocean (Stephens and Platt 1987; Boers and Krummel 1998; Boers et al. 1996) have demonstrated that $N_{d}$ generally decreases with increasing altitude while $r_{e}$ shows the reverse trend, which is consistent with the occurrence of droplet growth by collision-coalescence. Similar vertical variations of $N_{d}$ are also observed in midlatitude warm clouds and Arctic warm clouds as summarized by Gultepe and Isaac (2004). In recent observations over the southeastern Pacific Ocean, Terai et al. (2014) found that there is major vertical stratification of $N_{\mathrm{ccn}}$ such that measurements at the surface can be an order of magnitude higher than those at the level of the main cloud deck within the pockets of open cells (POCs). For observations near the top of the planetary boundary layer (PBL), $N_{d}$ scaled strongly with vertical motion within active cumulus $\left(\mathrm{Cu}\right.$; Wood et al. 2011). Further, $N_{d}$ and $N_{\text {ccn }}$ within POCs were found to be extremely low $\left(\sim 5 \mathrm{~cm}^{-3}\right.$ in the mean), demonstrating that in-cloud collision-coalescence can be efficient in depleting $N_{d}$ and $N_{\mathrm{ccn}}$, especially in the upper MBL and prompting characterization of these layers as ultraclean layers (UCLs; Sharon et al. 2006; Wood et al. 2011).

In Wood et al. (2018, hereafter Part I), we demonstrated that during the Cloud System Evolution in the Trades (CSET) field program (July-August 2015; subtropical northeastern Pacific), the NSF-NCAR Gulfstream V (G-V) aircraft frequently encountered UCLs, which were therein defined as layers of either cloud or clear air in which the concentration of particles larger than $0.1 \mu \mathrm{m}$ is below $10 \mathrm{~cm}^{-3}$ (see Part I for details regarding the definition of UCLs). We showed that the clouds in the UCLs are typically geometrically thin and were commonly the veil clouds associated with aggregated $\mathrm{Cu}$ clusters. Visible satellite images indicate that a large fraction of clouds observed in the UCLs were optically thin $(\tau<3)$. In part, this is caused by the extremely low $N_{d}$ in the UCL clouds (see discussion in Part I). Aircraft in situ measurements showed that (i) UCL coverage in CSET was as high as $40 \%-60 \%$ between $135^{\circ}$ and $155^{\circ} \mathrm{W}$ [i.e., stratocumulus-to-cumulus transition (SCT) region with deep PBL height] but that UCLs occurred very infrequently $(<10 \%)$ east of $130^{\circ} \mathrm{W}$ (i.e., the low-topped near-coastal stratocumulus region); (ii) UCLs are most commonly found at a height of $1.5-2 \mathrm{~km}$, typically close to top of the PBL; and (iii) $r_{e}$ in the UCL clouds is $\sim 20 \mu \mathrm{m}$ in the mean, which is twice as large as the mean $r_{e}$ in the non-UCL clouds (i.e., $N_{d}>$ $10 \mathrm{~cm}^{-3}$; see Fig. 1).

Based on the analysis of the aircraft measurements summarized in Part I, we hypothesize that the observed UCLs most likely result from efficient collisioncoalescence in the upper MBL over the SCT region. The deep PBL height $(\sim 1500 \mathrm{~m})$ in the SCT region gives high $q_{L}$ in the active trade $\mathrm{Cu}$ towers. It provides an opportunity for collision-coalescence to sufficiently deplete $N_{d}$ and hence could result in the formation of UCL clouds with extremely low $N_{d}$ and large $r_{e}$ in the upper MBL. Detrainment of cloudy air from the $\mathrm{Cu}$ towers forms horizontally extensive, thin cloud layers in the upper MBL with extremely low $N_{d}$ and low cloud optical depth as indicated by the satellite data (see Part I). Upon evaporation of UCL clouds, only a few accumulation mode particles are returned to the clear sky, which could leave the upper MBL strongly depleted in $N_{\text {ccn }}$.

In this work, we quantitatively test the proposed hypothesis for the formation process of the UCLs using idealized microphysical parcel model. The focus is on the depletion of $N_{d}$ and $N_{\text {ccn }}$ through in-cloud collisioncoalescence. An adiabatic two-dimensional (i.e., spanning droplet and aerosol dry size) bin parcel model is chosen as our main tool to test the hypothesis. The details of the model formulation are furnished in section 2 . 


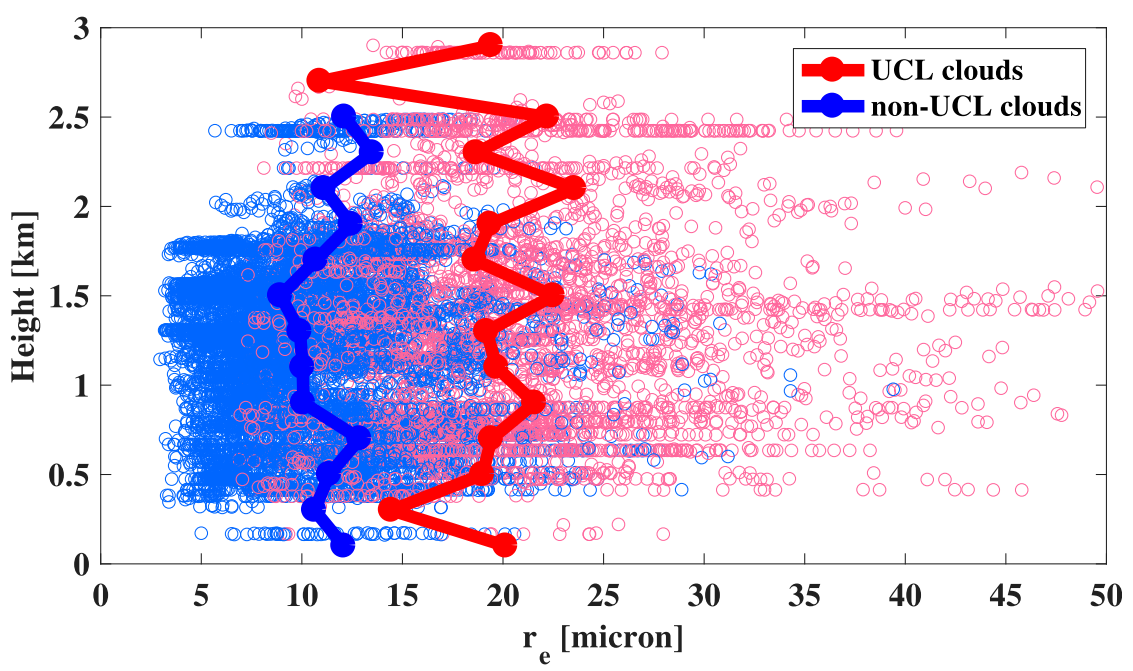

FIG. 1. Cloud droplet effective radius $r_{e}$ of UCL clouds (red) and non-UCL clouds (blue) measured during CSET. The blue and red lines are the mean $r_{e}$ for non-UCL clouds and UCL clouds, respectively. The calculation of $r_{e}$ is based on the measured DSDs of the CDP and 2DC probes. UCL cloud is defined as the cloudy layer with $N_{d}<10 \mathrm{~cm}^{-3}$, and non-UCL cloud is defined as the cloudy layer with $N_{d}>10 \mathrm{~cm}^{-3}$. The criterion used to separate the saturated cloudy samples from the unsaturated clear-air samples can be found in Part I.

Section 3 gives the parcel model results showing the temporal evolution of cloud microphysical processes in an idealized rising parcel in typical cumulus and stratocumulus regimes. In section 4 , by obtaining the best fit with the in situ measurements of cloud droplet size distributions (DSDs) from CSET, a bulk parameterization of the droplet coalescence-scavenging rate $\left[\dot{N}_{d}\right]_{\mathrm{cs}}$ is derived from the stochastic collection equation as a function of $N_{d}$ and $q_{L}$. With the parameterization, the relative importance of updraft, aerosol concentration, cloud thickness, and adiabaticity in coalescence-scavenging process are accessed. Section 5 offers a conclusion.

\section{Parcel model}

\section{a. Basic model formulations}

A Lagrangian adiabatic parcel model with explicit two-dimensional bin microphysics spanning aerosol and water droplet sizes is formulated to simulate the evolution of cloud microphysical processes in a rising parcel. First, the trajectory of the parcel follows an adiabatic ascent with a constant vertical velocity $U_{z}$. After the parcel reaches the assumed height of cloud top $z_{\text {top }}$, we include a period where the parcel moves horizontally at the cloud-top layer with $U_{z}=0$ (see Fig. 2). Cloud microphysical processes are considered by holding the particles on a two-dimensional grid, and each grid point is characterized by the sizes of the aerosol and the water droplet. Grid spacing for the aerosol size (i.e., dry size) and the water droplet size (i.e., wet size) are logarithmically spaced. The grid of the droplet size starts and ends at $D_{d}=0.02$ and $0.7 \mathrm{~cm}$. The aerosol size grid spans from $D_{a}=0.016$ to $0.4 \mathrm{~cm}$. Both liquid water and aerosol grids have 40 bins resulting in total 1600 bins in the $2 \mathrm{D}$ grid space. The model is integrated with the time step of $0.05 \mathrm{~s}$.

The prognostic thermodynamics variables are temperature and saturation ratio, and the microphysical processes that are explicitly simulated in the model are activation of aerosol, condensation-evaporation, interstitial scavenging, collision-coalescence, and droplet loss from the parcel by sedimentation (the details regarding the treatments of droplet sedimentation process in the parcel model are given below). Details of the equations describing condensation and the changes of the thermodynamic variables applied in the model can be found in the appendix of Korolev and Mazin (2003). There is no artificial separation between unactivated aerosols, activated cloud droplets, and drizzle. The nucleation of unactivated aerosol (i.e., haze particles) is explicitly calculated by solving the droplet growth equations with $\kappa$-Kohler parameterization for aerosol hygroscopicity developed by Petters and Kreidenweis (2007; the details regarding the size distribution and $\kappa$ value of aerosol are given later).

Collision-coalescence increases not only the size of water droplets but also size of the aerosol inside. The advantage of the 2D bin framework is that the resulting aerosol mass can be saved after collision-coalescence takes place, which may be important for the temporal evolution of DSDs. The hybrid bin scheme developed by 


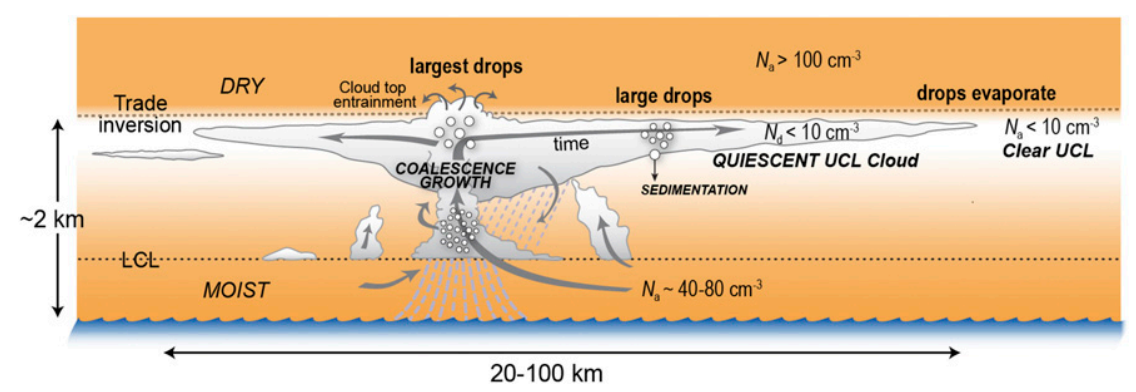

FIG. 2. Conceptual diagram of the formation of UCLs in the Sc-Cu transition.

Chen and Lamb (1994; CL scheme) is applied to treat condensation and evaporation processes. The twodimensional flux method developed by Bott (2000; Bott scheme) is used to treat collision-coalescence in the $2 \mathrm{D}$ bin framework. Both the CL scheme and the Bott scheme are mass conservative and numerically efficient. The CL scheme is a two-moment explicit scheme designed for the evolution of the DSDs by condensationevaporation, which produces little numerical diffusion and can be implemented into the 2D bin framework. The Bott scheme is an advanced method introducing the flux method for the stochastic collection equations developed by Bott (1998) into the 2D bin framework with low artificial broadening of DSDs. The gravitational collection kernel is applied here and can be given by $K\left(r, r^{\prime}\right)=E_{c} \pi\left(r+r^{\prime}\right)^{2}\left|V_{T}(r)-V_{T}\left(r^{\prime}\right)\right|$ (where $E_{c}$ is the collision efficiency, $r$ and $r^{\prime}$ are the radius of droplets, and $V_{T}$ is the terminal velocity of droplet). The collision efficiency $E_{c}$ used in the collection kernel is based on the combination of data from Hall (1980) and Rogers and Yau (1989). The coalescence efficiency is set to unity. The inertial scavenging is considered in the model with the collection kernel for inertial scavenging developed by Berner et al. (2013). It is shown later that aerosol activation is the dominant process depleting $N_{\mathrm{ccn}}$, and inertial scavenging does not contribute significantly to the depletion of $N_{\mathrm{ccn}}$ in the cloud regime investigated here. The terminal particle velocity $V_{T}$ is based on the relationship of $V_{T}$ with $D_{d}$ given in Pruppacher and Klett (2012).

\section{b. Initial conditions and aerosol distribution}

A set of initial conditions must be specified to run the model. The initial temperature $T_{0}$, the initial saturation ratio $S_{0}$, and the initial pressure $P_{0}$ are specified to be $300 \mathrm{~K}, 0.8$, and $1013 \mathrm{hPa}$, respectively, which are typical of the lower MBL and give the cloud-base $z_{\text {base }}$ [i.e., lifting condensation level (LCL)] $\sim 500 \mathrm{~m}$. The average normalized aerosol size distribution from the surface legs $(z<170 \mathrm{~m})$ of 16 flights during CSET is used to specify the initial aerosol dry size spectrum in the model.
The average aerosol size distribution shown in Fig. 3 is the combination of data from two probes, an ultra-highsensitivity aerosol spectrometer (UHSAS; $0.06<D_{a}<$ $1 \mu \mathrm{m})$ and a cloud droplet probe (CDP; $\left.D_{a}>1 \mu \mathrm{m}\right)$. The CDP can quantify giant $\mathrm{CCN}$ (GCCN). The ambient size given by CDP is corrected to the dry size by using a growth factor for sea salt of 1.8 as reported in Zhang et al. (2014). The sensitivity of the model results to GCCN is tested by removing GCCN from the initial aerosol input. The results (not shown) indicate that for the cloud regimes investigated here (i.e., in terms of number concentration of aerosol, aerosol size distribution, cloud-top height, and updraft speed), removal of GCCN from the initial aerosol input does not significantly change the temporal evolution of $N_{d}$ and $N_{\text {ccn }}$ in a rising parcel. GCCN could be relatively more important in the regime with more aerosol and lower cloud-top height. To thoroughly explore the importance of GCCN for the droplet coalescence-scavenging rate, a more comprehensive study is needed to test the sensitivity to GCCN in various cloud regimes, which is not our focus in this study. Clarke et al. (2006) reported the mean aerosol size distribution over the coastal regions of Hawaii (i.e., the northeastern Pacific, which is the same area investigated in this study) with average $10-\mathrm{m}$ wind speed of $\sim 7 \mathrm{~m} \mathrm{~s}^{-1}$. Note that the measurements in CSET only provide the aerosol size distribution with $D_{a}>$ $0.06 \mu \mathrm{m}$. To completely include the Aitken mode aerosol $\left(D_{a}<0.1 \mu \mathrm{m}\right)$, the aerosol concentration in size range $0.016<D_{a}<0.06 \mu \mathrm{m}$ from Clarke et al. (2006) is included in the initial aerosol size distribution. The total initial aerosol concentration assigned in the parcel model will be discussed in section 3 . The $\kappa$ value of aerosols is specified to be 0.8 , which is typical at the surface over the northeastern Pacific according to a recent modeling study [see Figs. 3 and 5 in Pringle et al. (2010)]. When the initial aerosol size distribution is introduced into the $2 \mathrm{D}$ aerosol and cloud bin spectrum, the initial equilibrium wet size of the aerosol is calculated based on the $\kappa$-Kohler equation with the specified $\kappa$ value and the initial conditions of $S_{0}, P_{0}$, and $T_{0}$. 


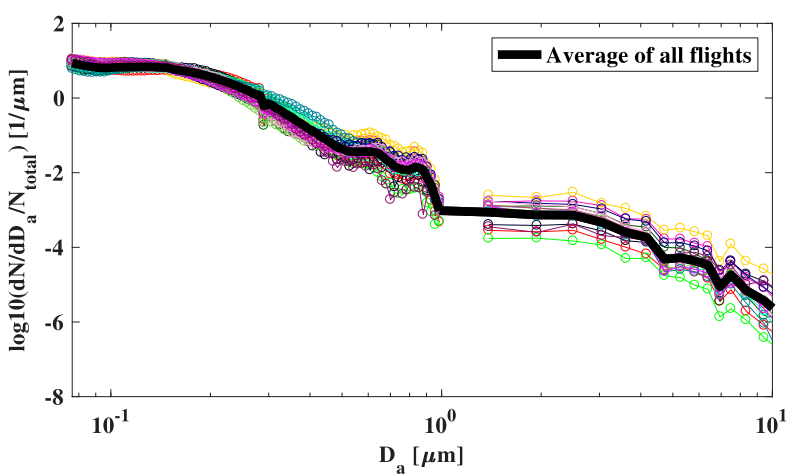

FIG. 3. Average normalized aerosol size distribution from CSET surface legs $(z<170 \mathrm{~m})$ of 16 flights (colors with circles) based on the UHSAS and CDP probes. The black line is the average normalized aerosol size distribution from all flights.

\section{c. Treatment of droplet sedimentation in the parcel model}

A significant deficiency of the Lagrangian parcel model is that droplet loss from the parcel by sedimentation is typically not taken into account. This may lead to unrealistic rates of collision-coalescence leading to the formation of millimeter-size drops with fall speeds substantially faster than the updrafts. Such deficiency in the Lagrangian approach can be avoided in Eulerian modeling frameworks like large-eddy simulation (LES), which explicitly calculate droplet loss rate by sedimentation. On the other hand, in the Eulerian framework, the complexity of microphysical schemes is usually limited by computational resources, and cloud microphysical processes must typically be parameterized. With a focus in this study on microphysical processes for UCLs formation, we choose the 2D bin microphysics parcel model as the tool for our modeling study. However, we also wish to consider the droplet loss due to sedimentation in the Lagrangian parcel model, and to achieve this, a simple treatment is selected and tested.

According to Houze (2014), with an assumption that the parcel has thickness $h_{p}$, the sedimentation loss rate of given size droplets in a parcel can be approximated by the sedimentation flux

$$
\left[\dot{N}_{i, j}\right]_{\mathrm{sedi}}=-N_{i, j} V_{T, j} / h_{p},
$$

where $i$ and $j$ denote the aerosol dry size bin and droplet wet bin on the two-dimensional grid. A two-step process is applied in the sedimentation flux method and is similar to the treatment in the $2 \mathrm{D}$ collision-coalescence scheme proposed by Bott (2000). We first integrate the 2D particle spectrum over the aerosol dry size, which yields a one-dimensional (1D) droplet spectrum as a function of the droplet size. In the next step, the flux loss rate of droplet given in Eq. (1) is applied to each grid box of this intermediate spectrum. In the last step, the resulting new droplet spectrum is redistributed into the $2 \mathrm{D}$ bin grids based on the fraction of droplets over the aerosol size grid. The parcel thickness $h_{p}$ is specified to be $100 \mathrm{~m}$ and is also used to specify the depth of the cloud-top layer (i.e., cloud-top detrainment layer) in the simulation.

The most uncertain factor in the sedimentation flux method is $h_{p}$, which requires an assumption of the parcel thickness. It is shown later that there is only a weak sensitivity to $h_{p}$ assumed in the model. In general, there is no perfect treatment for the droplet sedimentation process in the Lagrangian parcel model, so we will perform sensitivity tests to ensure our conclusion on the microphysical process of the UCLs is consistent among the parcel model runs with different assumed values of $h_{p}$.

\section{Parcel modeling results}

In Part I, analysis of the aircraft measurements in CSET found that UCLs are commonly found between $135^{\circ}$ and $155^{\circ} \mathrm{W}$ over the northeastern Pacific, the typical SCT region, but occur infrequently east of $130^{\circ} \mathrm{W}$ over the northeastern Pacific, the overcast stratocumulus region. We showed that the UCL clouds are commonly the veil clouds associated with the aggregated $\mathrm{Cu}$ clusters. This implies that the cumulus regime is favorable for the formation of UCLs. Here, two sets of idealized modeling experiments representing the temporal evolution of cloud microphysics in a rising parcel in stratocumulus $(\mathrm{Sc})$ and $\mathrm{Cu}$ are presented. According to Eastman et al. (2017), retrievals of PBL height from Moderate Resolution Imaging Spectroradiometer (MODIS) CALIPSO and COSMIC GPS radio occultation show that the typical cloud-topped PBL heights at $20^{\circ}-40^{\circ} \mathrm{N}$ are $1500 \mathrm{~m}$ between $135^{\circ}$ and $155^{\circ} \mathrm{W}$ (i.e., $\mathrm{Cu}$ regime) and $800 \mathrm{~m}$ east of $130^{\circ} \mathrm{W}$ (i.e., Sc regime) over the northeastern Pacific. These values are used to specify $z_{\text {top }}$ in the parcel modeling for the $\mathrm{Cu}$ and Sc regimes, respectively. The updraft speeds $U_{z}$ in MBL clouds are typically $0.1-3 \mathrm{~m} \mathrm{~s}^{-1}$, and $U_{z}$ in cumulus is typically more vigorous than in stratocumulus (Comstock et al. 2007; Gerber et al. 2008; Ghate et al. 2011). Updraft velocity can influence both in-cloud times available for air parcels rising through a cloud and the maximum supersaturation ratio in a cloud updraft. The updraft speed $U_{z}$ in the base cases for the $\mathrm{Cu}$ and $\mathrm{Sc}$ regimes are specified to be 0.75 and $0.25 \mathrm{~m} \mathrm{~s}^{-1}$, respectively. We will explore the sensitivity to updraft in both regimes by considering updraft velocities of 0.1 and $3 \mathrm{~m} \mathrm{~s}^{-1}$. In the following discussion, $N_{d}$ is defined as the number concentration of the particles with diameter $\geq 1 \mu \mathrm{m}$, and $N_{\text {ccn }}$ is defined 


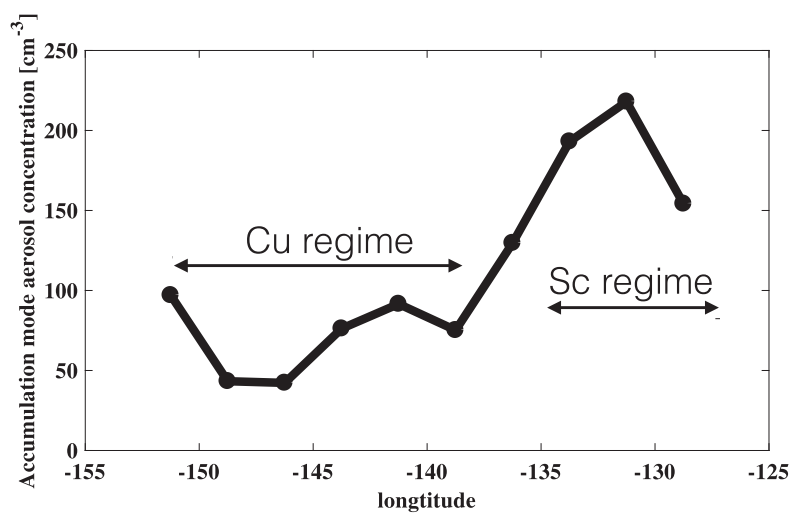

FIG. 4. Average accumulation mode aerosol concentration from CSET surface legs $(z<170 \mathrm{~m})$ as a function of longitude based on the UHSAS probe.

as the number concentration of the particles with diameter $<1 \mu \mathrm{m}$. The initial aerosol concentration with $D_{a}>0.06 \mu \mathrm{m}$ is based on the mean near-surface (i.e., $z<170 \mathrm{~m}$ ) aerosol concentration measured by the UHSAS probe $\left(1>D_{a}>0.06 \mu \mathrm{m}\right)$ during CSET (Fig. 4) and is specified to be $75 \mathrm{~cm}^{-3}$ (i.e., the mean value at $135^{\circ}-155^{\circ} \mathrm{W}$, the typical cumulus regime) in the $\mathrm{Cu}$ regime and $200 \mathrm{~cm}^{-3}$ (i.e., the mean value at $125^{\circ}$ $132.5^{\circ} \mathrm{W}$, the typical stratocumulus regime) in the Sc regime. Sensitivity tests on the initial aerosol condition by swapping input aerosol concentration in the $\mathrm{Cu}$ and $\mathrm{Sc}$ base cases are performed and will be discussed. Note that the near-surface concentration of GCCN with $D_{a}>$ $1 \mu \mathrm{m}$ measured by CDP is mostly $<1 \mathrm{~cm}^{-3}$ in CSET. The aerosol concentration $\left(\sim 7 \mathrm{~cm}^{-3}\right)$ and size distribution with $D_{a}<0.06 \mu \mathrm{m}$ from Clarke et al. (2006) is included in the initial aerosol distribution in both regimes to completely include the Aitken mode aerosol. A summary of the setups and the results of the $\mathrm{Cu}$ and $\mathrm{Sc}$ cases simulated in this study is given in Tables 1 and 2. The discussion regarding liquid water content $q_{L}$ in the parcel modeling will be given in section 4 .

\section{a. Cumulus regime}

Figure 5 shows the base case for the $\mathrm{Cu}$ regime, which suggests the $\mathrm{Cu}$ regime is favorable for the formation of UCLs and supports our hypothesis. The modeling result shows that $N_{d}$ is strongly depleted in the cumulus updraft ( $>80 \%$ depletion of $N_{d}$ ), leading to the occurrence of UCL clouds at the cloud-top layer. Figure $5 \mathrm{~d}$ shows the fraction of droplet loss caused by collisioncoalescence, droplet sedimentation, and evaporation. It indicates that collision-coalescence within the parcel is the dominant process in depleting $N_{d}$ and the formation of UCLs in the $\mathrm{Cu}$ regime. The temporal evolution of $r_{e}$ is shown in Fig. $5 \mathrm{~b}$ with the black line, indicating
TABLE 1. Summary of the setups and the results of the cumulus cases simulated in this study. Initial $N_{\text {ccn }}$ includes both Aitken mode and accumulation mode aerosol measured during CSET and from Clarke et al. (2006), where $z_{\text {top }}$ is the cloud-top height, $U_{z}$ is the parcel updraft, and $\bar{r}_{e}$ is the average effective radius.

\begin{tabular}{lcccc}
\hline \multicolumn{1}{c}{ Parameters } & \multicolumn{4}{c}{ Cu cases } \\
\hline Figure & Fig. 5 & Figs.7a-e & Figs. 7f-j & Figs. 11a-e \\
Initial $N_{\text {ccn }}\left(\mathrm{cm}^{-3}\right)$ & 77 & 77 & 77 & 207 \\
$z_{\text {top }}(\mathrm{m})$ & 1500 & 1500 & 1500 & 1500 \\
$U_{z}\left(\mathrm{~m} \mathrm{~s}^{-1}\right)$ & 0.75 & 0.1 & 0.3 & 0.75 \\
$\bar{r}_{e}$ of UCL & 20 & 19 & 21 & 17 \\
$\quad \begin{array}{l}\text { clouds }(\mu \mathrm{m}) \\
\text { UCL formation }\end{array}$ & Yes & Yes & Yes & Yes \\
\hline
\end{tabular}

considerable growth of droplet size in the $\mathrm{Cu}$ updraft by collision-coalescence. Cloud droplets can grow through condensation and collision-coalescence. By using an analytical expression for diffusional droplet growth, Pinsky et al. (2014) has shown that without including the collision-coalescence process, $r_{e}$ of droplets in warm liquid clouds can hardly reach $15 \mu \mathrm{m}$ by condensation alone [see Fig. 6 in Pinsky et al. (2014)]. Thus, the substantial growth of $r_{e}$ shown in the parcel modeling and the large $r_{e}$ in UCL clouds observed during CSET (20 $\mu \mathrm{m}$ in the mean; see Fig. 1) must be due to collisioncoalescence. The modeling results show that $r_{e}$ can be larger than $\sim 30 \mu \mathrm{m}$ in the UCL clouds (black line in Fig. 5b), and such large droplet size in the UCL clouds is also observed during CSET, as shown in Fig. 1. After the parcel has reached its assumed maximum height, because of the relatively large droplet loss caused by droplet sedimentation (black line in Fig. 5c), $r_{e}$ in the UCL clouds decreases gradually. This may explain why the UCL cloudy samples observed during CSET have relatively large spread in $r_{e}$ (see Fig. 1). After the parcel stops lifting, droplet sedimentation gradually becomes the primary process depleting $N_{d}$ (see Fig. $5 \mathrm{~d}$ ) with very low droplet loss rate and very low droplet concentration $\left(<5 \mathrm{~cm}^{-3}\right)$. The results presented here suggest that there

TABLE 2. As in Table 1, but for the stratocumulus cases.

\begin{tabular}{lcccc}
\hline \multicolumn{1}{c}{ Parameters } & \multicolumn{4}{c}{ Sc cases } \\
\hline $\begin{array}{l}\text { Figure } \\
\text { Initial } N_{\text {ccn }}\left(\mathrm{cm}^{-3}\right)\end{array}$ & Fig. 9 & Figs. 10a-e & Figs. 10f-j & Figs. 11f-j \\
$z_{\text {top }}(\mathrm{m})$ & 800 & 207 & 207 & 77 \\
$U_{z}\left(\mathrm{~m} \mathrm{~s}^{-1}\right)$ & 0.25 & 0.1 & 800 & 800 \\
$\bar{r}_{e}$ of UCL & - & 10 & - & - \\
$\quad \begin{array}{c}\text { clouds }(\mu \mathrm{m}) \\
\bar{r}_{e} \text { of non-UCL } \\
\quad \text { clouds }(\mu \mathrm{m})\end{array}$ & 8 & 9 & 10 & 10 \\
\begin{tabular}{l} 
UCL formation \\
\hline
\end{tabular} & No & Yes & No & No \\
\hline
\end{tabular}


(a)

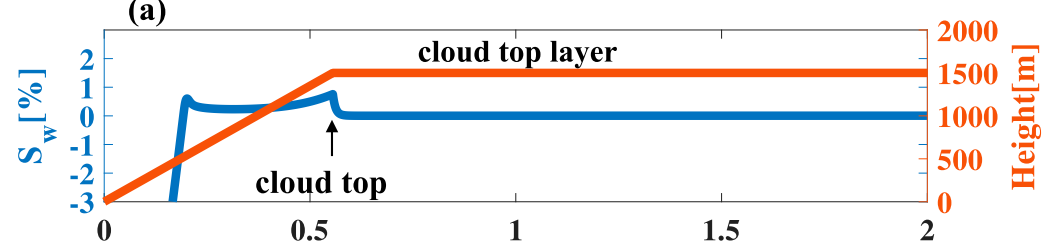

(b)

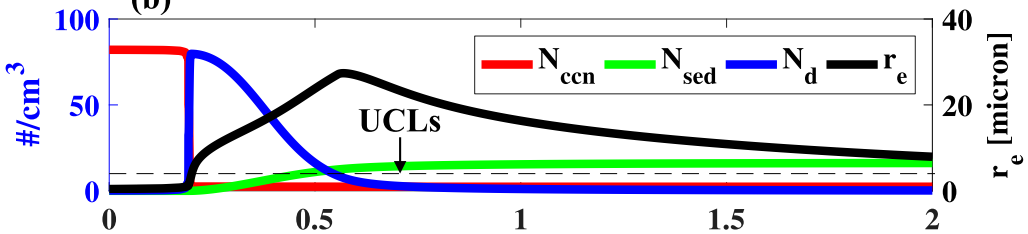

(c)

time $[\mathrm{hr}]$

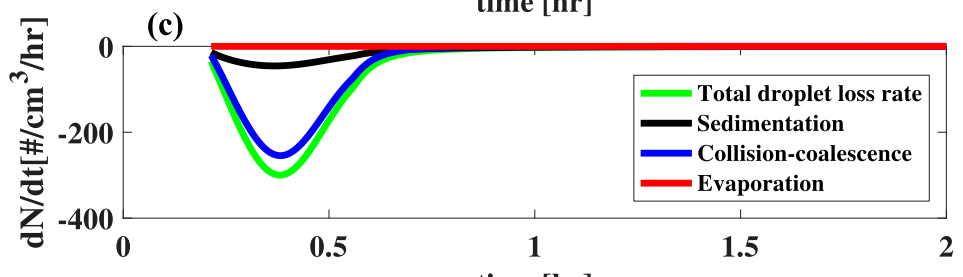

(d)

time $[\mathrm{hr}]$
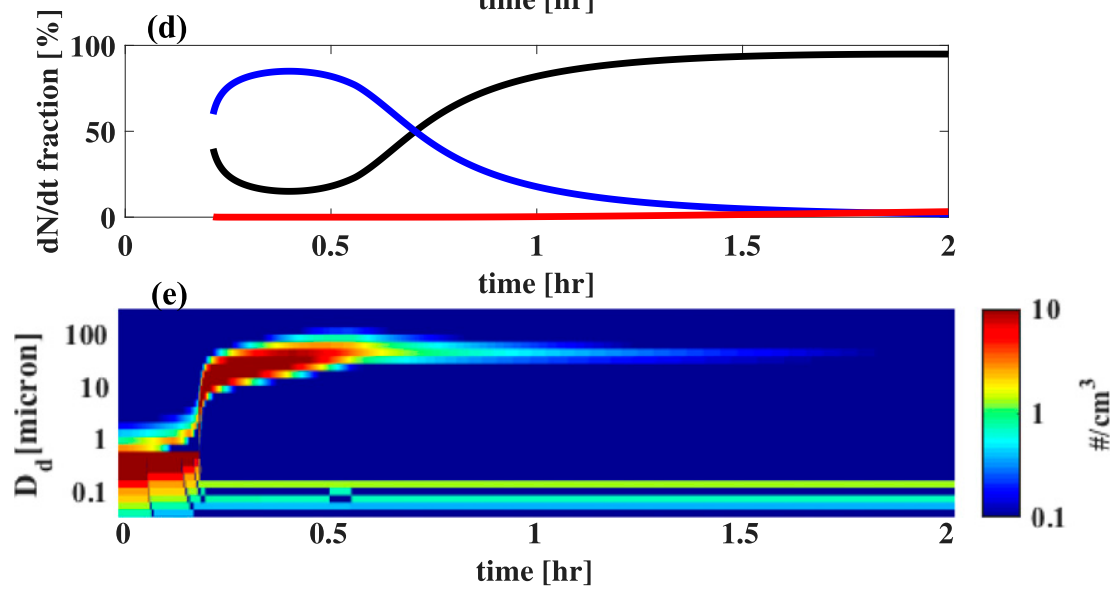

FIG. 5. Cumulus base case with $U_{z}$ of $0.75 \mathrm{~m} \mathrm{~s}^{-1}$. (a) Height (orange) and supersaturation ratio (blue) of the parcel; (b) temporal evolution of number concentration of cloud condensation nuclei $N_{\text {ccn }}$ (red), droplet sedimentation $N_{\text {sed }}$ (green), cloud droplet $N_{d}$ (blue), and effective radius of droplet $r_{e}$ (black) in the parcel, and the black dashed lines indicates a particle concentration of $10 \mathrm{~cm}^{-3}$; (c) total droplet loss rate (green) and the droplet loss rate by sedimentation (black), collision-coalescence (blue), and evaporation (red); (d) fraction of droplet loss rate by sedimentation (black), collision-coalescence (blue), and evaporation (red); and (e) temporal evolution of DSDs in the parcel.

is a transition of dominant cloud microphysics process from the updraft to the cloud-top layer such that the depletion of $N_{d}$ is dominated by collision-coalescence resulting in the increase of $r_{e}$ in the updraft, while at the cloud-top layer, sedimentation loss is the main process depleting $N_{d}$ and thus causes the decrease of $r_{e}$. MODIS retrievals of $r_{e}$ suggests that such behavior of $r_{e}$ is typical in the SCT region. Figure 6 shows that in the Cu clusters, $r_{e}$ (from 3.7- $\mu \mathrm{m}$ MODIS channel) reduces from $\sim 30 \mu \mathrm{m}$ at the updraft region to $\sim 10 \mu \mathrm{m}$ at the cloud edge, which is consistent with the sedimentation process at the cloud top shown by the parcel modeling presented here. The retrieval of $r_{e}$ using 2.1- $\mu \mathrm{m}$ MODIS channel shows the similar pattern (not shown) for all these selected cases. The schematic evolution of cloud microphysics in the cumulus updraft described here is summarized in Fig. 2.

The left column in Fig. 7 shows the parcel modeling results for the Cu regime but with an artificially small $U_{z}$ 


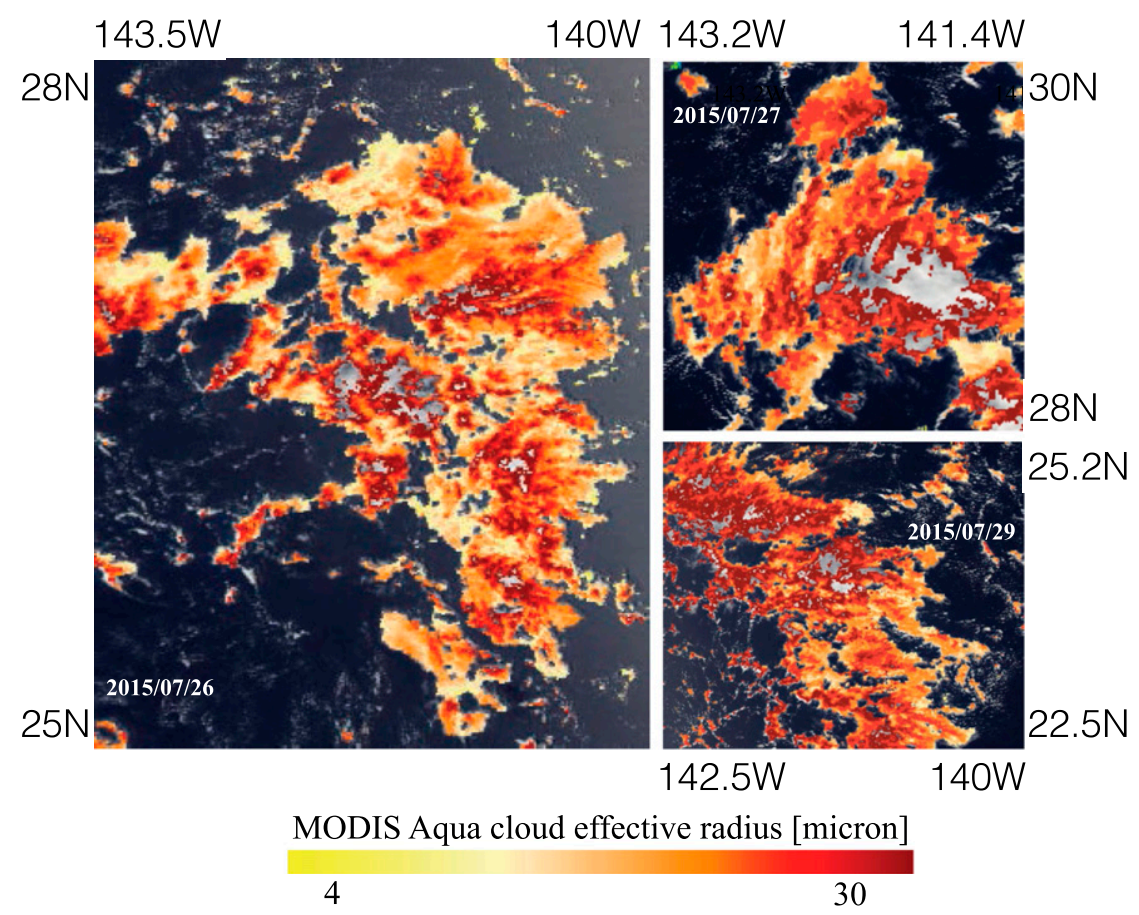

FIG. 6. MODIS retrieval of effective radius of $\mathrm{Cu}$ clusters in the $\mathrm{Sc}-\mathrm{Cu}$ transition $(3.7-\mu \mathrm{m}$ MODIS channel).

of $0.1 \mathrm{~m} \mathrm{~s}^{-1}$. The cumulus case with $U_{z}$ of $0.1 \mathrm{~m} \mathrm{~s}^{-1}$ has low $S_{\max }(\sim 0.2 \%)$ in the updraft, resulting in fewer particles activated at the cloud base than in the cases with $U_{z}$ of 0.75 and $3 \mathrm{~m} \mathrm{~s}^{-1}$ (Figs. 5 and $7 \mathrm{f}-\mathrm{j}$ ). The $N_{d}$ in the $\mathrm{Cu}$ updraft is strongly depleted by collisioncoalescence, which eventually causes the formation of UCLs in the updraft. In the case with low updraft of $0.1 \mathrm{~m} \mathrm{~s}^{-1}$, UCLs are formed at fairly low altitude $(\sim 1100 \mathrm{~m})$ even before the parcel reaches its assumed max height (i.e., $1500 \mathrm{~m}$ ). Note that in the $\mathrm{Cu}$ cases with $U_{z}$ of 0.75 and $3 \mathrm{~m} \mathrm{~s}^{-1}$, UCLs are formed after the parcel reaches the assumed cloud-top height. This indicates that slower $U_{z}$ can help the formation of UCLs at lower altitude, which can be linked to the updraft time scale $\tau_{\text {up }}$ (i.e., a parcel to ascend from base to top) as discussed in Ovchinnikov et al. (2013). A longer $\tau_{\text {up }}$ (i.e., slower $U_{z}$, given same cloud thickness) can provide longer incloud time in updraft for collision-coalescence to act to deplete $N_{d}$, so the formation of UCLs is favored by slower updrafts [see detailed discussion in Ovchinnikov et al. (2013)]. In addition to the maximum supersaturation $S_{\max }$ at the cloud base, there is a second maximum in $S_{w}$ occurring near the cloud top because of the substantial decrease of $N_{d}$ (i.e., depletion term for supersaturation ratio $S_{w}$ ) and constant $U_{z}$ in the $\mathrm{Cu}$ updraft [i.e., source term for $S_{w}$; see Eq. (2) in Pinsky et al. 2013], leading to multiple secondary activation events of small aerosols (see Fig. 7e) that cannot be activated at the cloud base. Secondary activation of aerosols not only increases $N_{d}$ but also hence slightly increases the droplet loss rate by collisioncoalescence [droplet loss rate by collision-coalescence is positively correlated with $N_{d}$; see Eq. (3) in section 4], which results in the blue jagged line of fraction of droplet loss by collision-coalescence shown in Fig. 7d.

The right column in Fig. 7 shows the parcel modeling result for the $\mathrm{Cu}$ regime with $U_{z}$ of $3 \mathrm{~m} \mathrm{~s}^{-1}$. Because of the high $U_{z}$ (i.e., $3 \mathrm{~m} \mathrm{~s}^{-1}$ ) assumed in this case, the available time for collision-coalescence to act to deplete $N_{d}$ in the updraft is much shorter than in the other two cases (i.e., $U_{z}=0.1$ and $0.75 \mathrm{~m} \mathrm{~s}^{-1}$ ). The fractional loss of $N_{d}$ from the cloud base to the cloud-top $f_{\text {top-loss }}$ is $\sim 50 \%$, which is lower than in the cases with $U_{z}$ of 0 and $0.75 \mathrm{~m} \mathrm{~s}^{-1}\left(f_{\text {top-loss }}>80 \%\right)$. In this case with high $U_{z}$, the maximum coalescence-scavenging rate (i.e., blue line in Fig. 7h) is at the cloud top. On the contrary, in the previous cases with relatively lower updraft speed (i.e., Fig. 5 and left column of Fig. 7), the maximum coalescence-scavenging rates are typically not at the cloud top and have much lower values (see blue lines in Figs. $5 \mathrm{c}, 7 \mathrm{c}$, and $7 \mathrm{~h}$ ). This is because the coalescencescavenging rate is positively correlated with $N_{d}$ and $q_{L}$ (see section 4 for details). In the cases with relatively low updraft (i.e., $U_{z}=0.1$ and $0.75 \mathrm{~m} \mathrm{~s}^{-1}$ ), most of $N_{d}$ is depleted before the parcel reaches the cloud top. When 
(a)

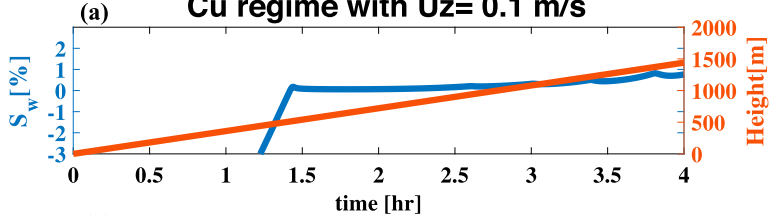

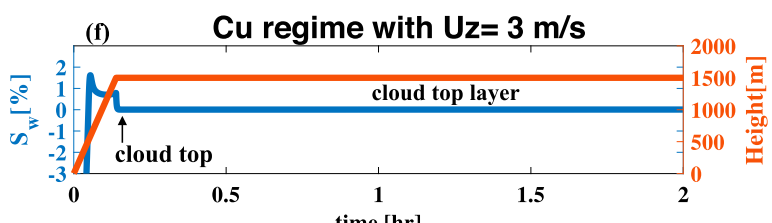
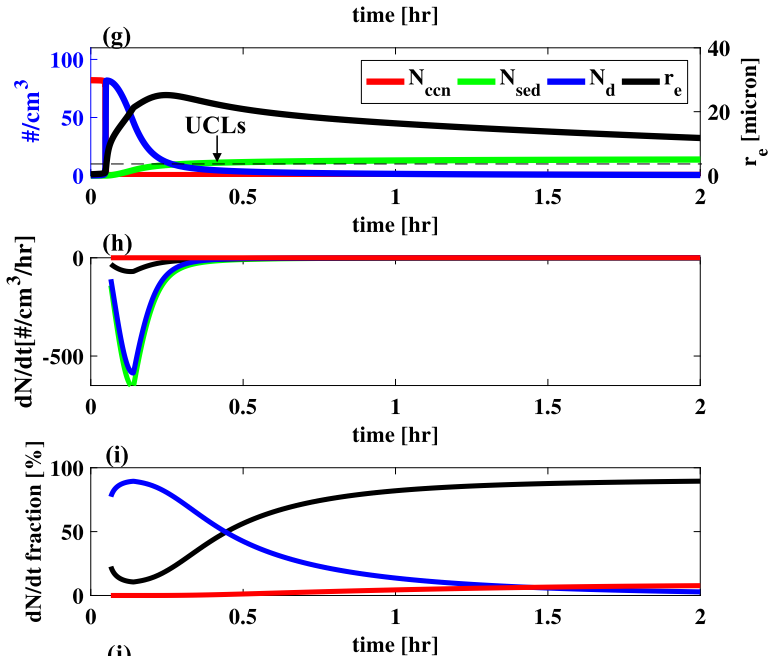

(j)

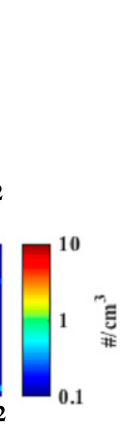

FIG. 7. Cu regime as in Fig. 5, but for $U_{z}=$ (a)-(e) 0.1 and (f)-(j) $3 \mathrm{~m} \mathrm{~s}^{-1}$.

the parcel reaches the cloud top, because of very low $N_{d}$ $\left(<10 \mathrm{~cm}^{-3}\right)$, the coalescence-scavenging rate is very low even though maximum $q_{L}$ in the adiabatic updraft is at the cloud top. In contrast, in the case with fast $U_{z}$, more than $50 \%$ of $N_{d}$ still remain in the parcel at the cloud top where adiabatic $q_{L}$ reaches its maximum in the updraft, resulting in the maximum coalescence-scavenging rate at the cloud top. Regarding the droplet size in the UCL clouds, both of the modeling results shown in Fig. 7 suggest that $r_{e}$ is $\sim 20 \mu \mathrm{m}$ in the UCL clouds, consistent with the observations shown in Fig. 1. The parcel modeling results for the $\mathrm{Cu}$ regime also suggest that UCL clouds contain a monomodal droplet size distribution, which is consistent with the observations summarized in Part I. This indicates that the bin model can produce a droplet spectrum in UCL clouds that is realistic compared with the observations. With the sensitivity test presented in Figs. 5 and 7 by considering a wide range of updraft speed in the $\mathrm{Cu}$ regime, we conclude that the parcel modeling results for the $\mathrm{Cu}$ regime agree well with the hypothesized microphysical process we proposed for UCL formation. The results indicate that in the $\mathrm{Cu}$ regime, collision-coalescence can cause the formation of UCL clouds by rapidly depleting $N_{d}$. Once the UCL clouds evaporate, this efficient coalescencescavenging process can result in very low $N_{\text {ccn }}$ in the upper MBL.

Figure 8 shows a sensitivity test of the $\mathrm{Cu}$ base case to the choice of $h_{p}$ applied in the sedimentation flux. The model runs with $h_{p}$ of 100,300 , and $500 \mathrm{~m}$ are demonstrated here. The results shown in Fig. 8 all suggest that collision-coalescence is the key physical process controlling the depletion of $N_{d}$ and droplet loss by sedimentation is of secondary importance. The comparison between three model runs in Fig. 8 suggests that in the parcel, there is a compensating feedback in the parcel modeling between collisioncoalescence and sedimentation processes in depleting $N_{d}$. When the parcel is assumed to be thinner (e.g., $h_{p}=100 \mathrm{~m}$ ), large drizzle-sized droplets tend to fall out of the parcel faster by sedimentation (i.e., depleting $N_{d}$ ), but this lowers the efficiency of collisioncoalescence by removing those drops that are the most efficient collectors, and vice versa. As a result of compensation between collision-coalescence and droplet sedimentation in the parcel model, the choice 

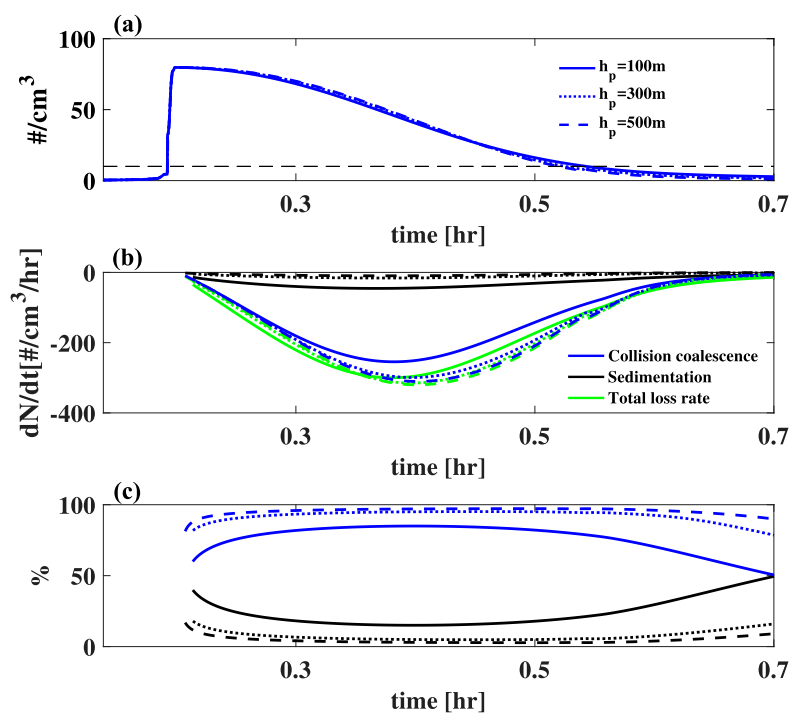

FIG. 8. Sensitivity test to the value of $h_{p}$ used in the $\mathrm{Cu}$ base case $\left(U_{z}=0.75 \mathrm{~m} \mathrm{~s}^{-1}\right.$ ) for $h_{p}=100$ (solid), 300 (dotted), and $500 \mathrm{~m}$ (dashed). (a) Temporal evolution of cloud droplet concentration $N_{d}$ in the parcel; (b) total droplet loss rate (green), droplet loss rate by collision-coalescence (blue), and sedimentation (black); and (c) fraction of droplet loss rate by sedimentation (black) and collision-coalescence (blue).

of $h_{p}$ applied in the parcel model does not result in major differences in the temporal evolution of $N_{d}$. The parcel modeling runs for the $\mathrm{Sc}$ regime and the $\mathrm{Cu}$ regime with different $U_{z}$ suggest the same compensating feedback (not shown). Thus, based on the sensitivity test presented in Fig. 8, we conclude that the sedimentation treatment applied in the parcel model does not affect our conclusion that collisioncoalescence is the process governing the formation of UCLs.

\section{b. Stratocumulus regime}

One important feature in stratocumulus is that usually parcels would be forced to descend by longwave cooling in a relatively shorter period of time than in cumulus, and the parcels could potentially pass stratocumulus multiple times. Here, we only allow the air parcel in Sc case to pass cloud layer only once in order to fairly compare the potential of UCLs formation in the stratocumulus cases and the cumulus cases (section 3a). The effect of multiple air parcel cycling on droplet depletion and it associated potential to produce UCLs in stratocumulus cloud will be discussed in section 4c. By using LES, Kogan (2006) showed that the residence time of air parcels at the cloud top is typically $<30 \mathrm{~min}$ in stratocumulus. Thus, in the parcel modeling runs for the Sc regime, the time for which parcels stay in the cloud-top layer is simply assumed to be $30 \mathrm{~min}$.
The modeling result of the Sc base case indicates that $\mathrm{Sc}$ regime is not favorable for the formation of UCLs (Fig. 9) as compared to the $\mathrm{Cu}$ regime. Although there is also an appreciable decrease of $N_{d}$ caused largely by collision-coalescence, the fractional loss of $N_{d}$ in the stratocumulus updraft is smaller than in the $\mathrm{Cu}$ updraft. The value of $N_{d}$ is $126 \mathrm{~cm}^{-3}$ when first reaching the cloud top, giving the fractional loss of $37.5 \%$ from the cloud base $\left(N_{d}\right.$ is $\sim 200 \mathrm{~cm}^{-3}$ at the cloud base). After the parcel stops lifting, there is a remarkable ripening effect (i.e., large droplets with positive growth rates continue to grow at the expense of small droplets with negative growth rates; Celik and Marwitz 1999; Wood et al. 2002), which results in the evaporation of small droplets and thus an increase of interstitial $N_{\text {ccn }}$ (see Fig. 9e) at the cloud-top level. Droplet evaporation can contribute about $10 \%$ of the droplet loss at the cloud-top level in the $\mathrm{Sc}$ regime. On the contrary, in the $\mathrm{Cu}$ case, there is nearly no evaporation because droplets in the $\mathrm{Cu}$ updraft can grow to larger sizes (which have saturation vapor pressure $\sim 100 \%$ ) because of higher $S_{\max }$ and more efficient collision-coalescence process in the $\mathrm{Cu}$ updrafts. At cloud-top level in the Sc base case, when there is still a considerable concentration of droplets and aerosols, the droplet depletion rate by collision-coalescence becomes very low, preventing the formation of UCLs at the cloud-top layer. The mean $r_{e}$ in the non-UCL clouds in the Sc base case is $\sim 10 \mu \mathrm{m}$, which is consistent with the in situ measurements summarized in Fig. 1.

The left column in Fig. 10 shows the modeling results for the Sc regime with $U_{z}$ of $0.1 \mathrm{~m} \mathrm{~s}^{-1}$. Because of low $S_{\max }$ caused by low $U_{z}$, a large fraction of aerosols are not activated at the cloud base. Because of long $\tau_{\text {up }}$ (because of low $U_{z}$ ) in the updraft and relatively small amount of activated aerosols compared with the Sc base case, UCL cloud $\left(N_{d}<10 \mathrm{~cm}^{-3}\right)$ is formed at the cloudtop layer mainly caused by collision-coalescence. This suggests that in the Sc regime, if $U_{z}$ is low enough, formation of UCL cloud is possible after the air parcel passes the stratocumulus layer only once, but because of low $S_{\max }$ and thus a large amount of unactivated aerosols remaining in the parcel, formation of a clear UCL (i.e., $N_{\mathrm{ccn}}<$ $\left.10 \mathrm{~cm}^{-3}\right)$ is difficult. Such low $U_{z}\left(\sim 0.1 \mathrm{~m} \mathrm{~s}^{-1}\right)$ in stratocumulus rarely occurs over the northeastern Pacific according to a recent observational study. Zheng et al. (2016) showed that observed cloud-base updraft in stratocumulus over the northeastern Pacific are typically in the range of $0.2-1 \mathrm{~m} \mathrm{~s}^{-1}$, which may explain why the observed occurrence of UCL clouds is fairly low $(<10 \%)$ in the stratocumulus decks observed in CSET, as we showed in Part I. The right column in Fig. 10 shows the Sc case with $U_{z}$ of $3 \mathrm{~m} \mathrm{~s}^{-1}$, suggesting that high $U_{z}$ in updraft can possibly result in a nearly constant vertical profile of $N_{d}$ in 
(a)

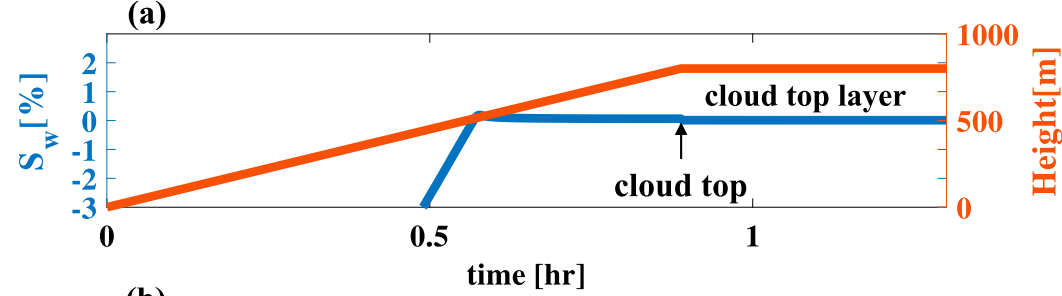

(b)

time $[\mathrm{hr}]$
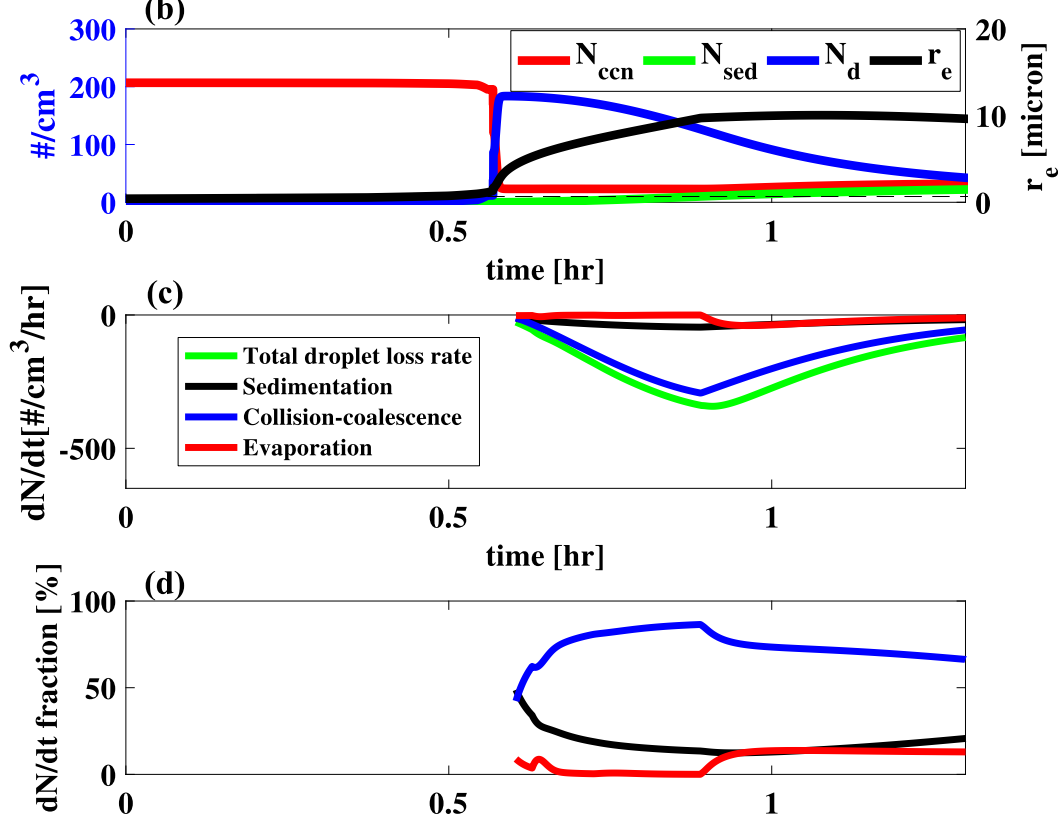

(e) time $[\mathrm{hr}]$

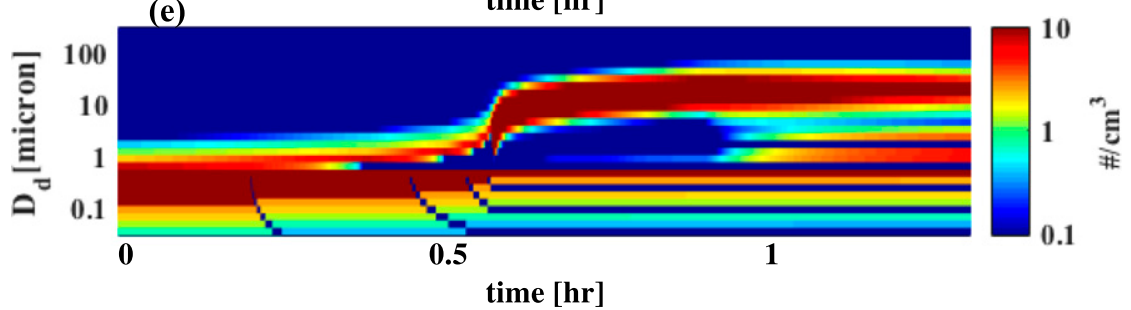

FIG. 9. As in Fig. 5, but for the stratocumulus regime.

stratocumulus, which is consistent with the previous discussion regarding fractional droplet loss and $\tau_{\text {up }}$ in the updraft. For both cases, $r_{e}$ in the non-UCL clouds is $\sim 10 \mu \mathrm{m}$, consistent with the in situ measurements shown in Fig. 1. Based on the parcel modeling results for the Sc regime shown in Figs. 9 and 10 with the sensitivity test on $U_{z}$, we conclude that the Sc regime is typically not favorable for UCL formation as compared to the $\mathrm{Cu}$ regime.

Although there are some major advantages to the adoption of a Lagrangian parcel model approach, especially for the study focus on cloud microphysical processes, there are two major caveats that should be addressed and discussed here: 1) the droplets falling into the parcel from above and 2) the entrainment of aerosol from free troposphere are not taken into account, which could be a significant source of droplet concentration in the rising parcel. However, large droplets falling from above could also increase the efficiency of collisioncoalescence by adding those drops that are the most efficient collectors, which can result in the compensating feedback as shown in Fig. 8. In addition, as shown in Part I, veil clouds in UCLs tend to be much less turbulent than non-UCL clouds in the same altitude, suggesting that the entrainment rate of aerosol from above into the veil clouds may be much lower than in the active cumulus updraft. Therefore, these arguments support the notion that the processes of sedimentation and entrainment do not affect our conclusion that strong collision-coalescence in the precipitating cumulus clusters is the dominant 

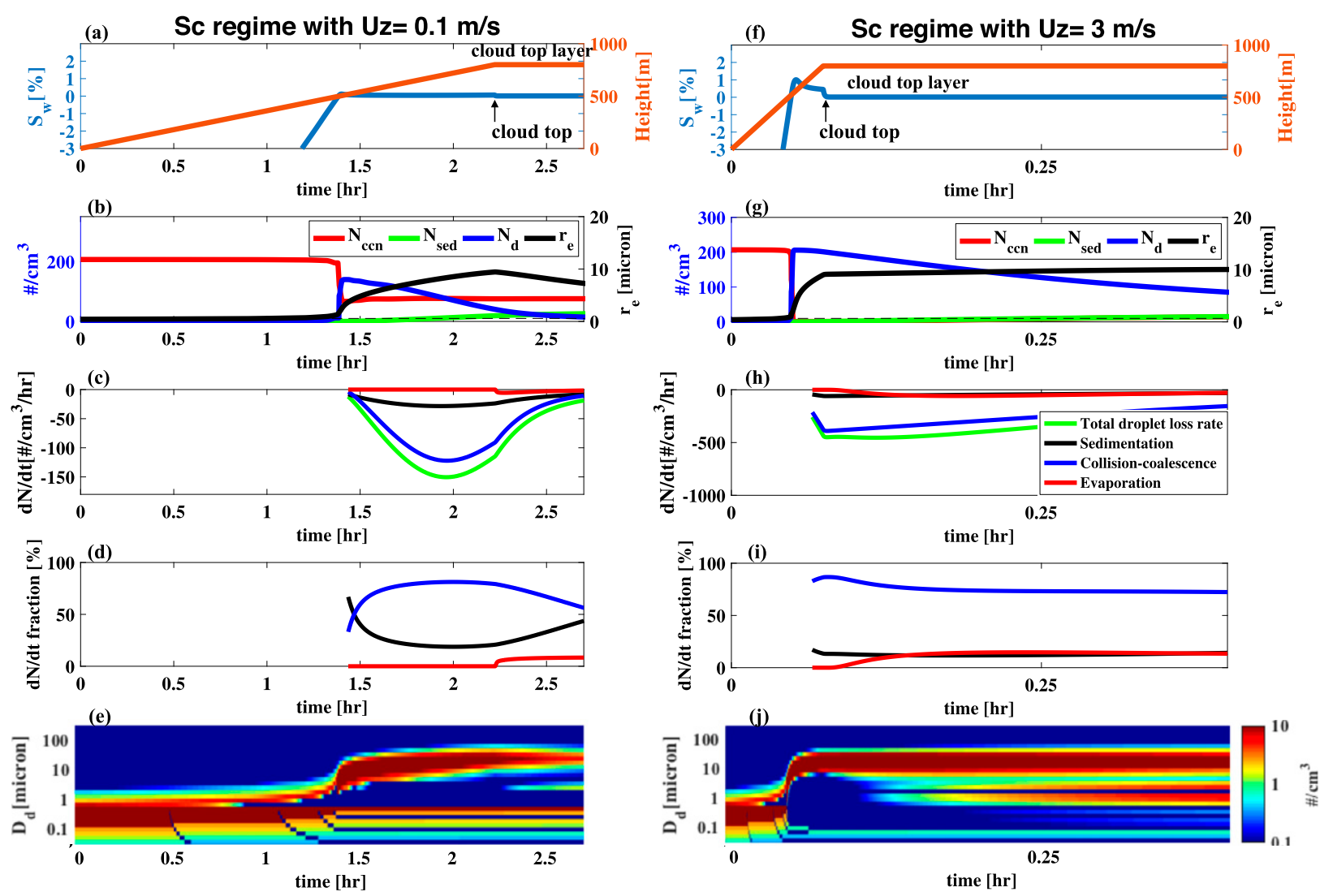

FIG. 10. Sc regime as in Fig. 8, but for $U_{z}=$ (a)-(e) 0.1 and (f)-(j) $3 \mathrm{~m} \mathrm{~s}^{-1}$.

process contributing to the prevailing UCLs feature throughout SCT regions.

\section{c. Sensitivity to the initial aerosol condition}

In this section, we aim to test the sensitivity of the modeling results to the initial aerosol condition assumed in the parcel model by swapping the initial $N_{\text {ccn }}$ assumed in the $\mathrm{Sc}$ and $\mathrm{Cu}$ base cases. The left column in Fig. 11 shows the $\mathrm{Cu}$ case (i.e., cloud top $=1500 \mathrm{~m}$ and $U_{z}=$ $0.75 \mathrm{~m} \mathrm{~s}^{-1}$ ) with an initial $N_{\mathrm{ccn}}$ of $207 \mathrm{~cm}^{-3}$. With relatively high initial $N_{\mathrm{ccn}}$, the Cu case still shows the formation of UCLs (i.e., low $N_{d}$ and large $r_{e}$ ) caused by dominant collision-coalescence process shortly after the parcel reaches the assumed cloud-top height $(1500 \mathrm{~m})$. This result indicates that the initial $N_{\text {ccn }}$ plays only a minor role in determining the formation of UCLs in the $\mathrm{Cu}$ regime. On the other hand, with initial $N_{\mathrm{ccn}}$ of $77 \mathrm{~cm}^{-3}$ assumed in the Sc case (Fig. 11, right column; i.e., cloud top = $800 \mathrm{~m}$ and $\left.U_{z}=0.25 \mathrm{~m} \mathrm{~s}^{-1}\right), N_{d}$ is depleted to $17 \mathrm{~cm}^{-3}$ after the parcel stays for $30 \mathrm{~min}$ at the cloud top, indicating that even with artificially low aerosol concentration, the Sc regime is still rather unfavorable for the formation of UCLs (i.e., $N_{d}<10 \mathrm{~cm}^{-3}$ ) as compared to the $\mathrm{Cu}$ regime. These two sensitivity experiments show that cloud thickness and liquid water amount are much more crucial factors than initial aerosol concentration for the formation of UCLs.

\section{Parameterization of droplet coalescence- scavenging rate}

\section{a. Derivation}

The stochastic collection equation (SCE) gives an expression for the droplet loss rate through coalescencescavenging $\left[\dot{N}_{d}\right]_{\text {cs }}$ (e.g., Wood 2006):

$$
\left[\dot{N}_{d}\right]_{\mathrm{cs}-\mathrm{SCE}}=-\frac{1}{2} \int_{0}^{\infty} \int_{0}^{\infty} n(r) n\left(r^{\prime}\right) K\left(r, r^{\prime}\right) d r d r^{\prime} .
$$

Given that each droplet coalescence event reduces the number of $\mathrm{CCN}$ by one, Eq. (2) can also be interpreted as being a loss rate for the CCN. To explicitly solve Eq. (2), a bin microphysics scheme and the full DSD is required. However, deployment of bin microphysics in a numerical model needs considerable computational expense, so the microphysical schemes in LES and general circulation models (GCMs) are mostly of the 
(a) Cu case with initial Nccn $=207 \mathrm{~cm}^{-3}$

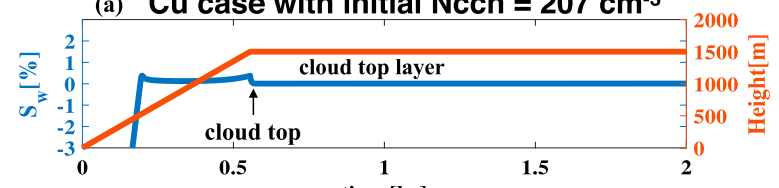

time [hr]
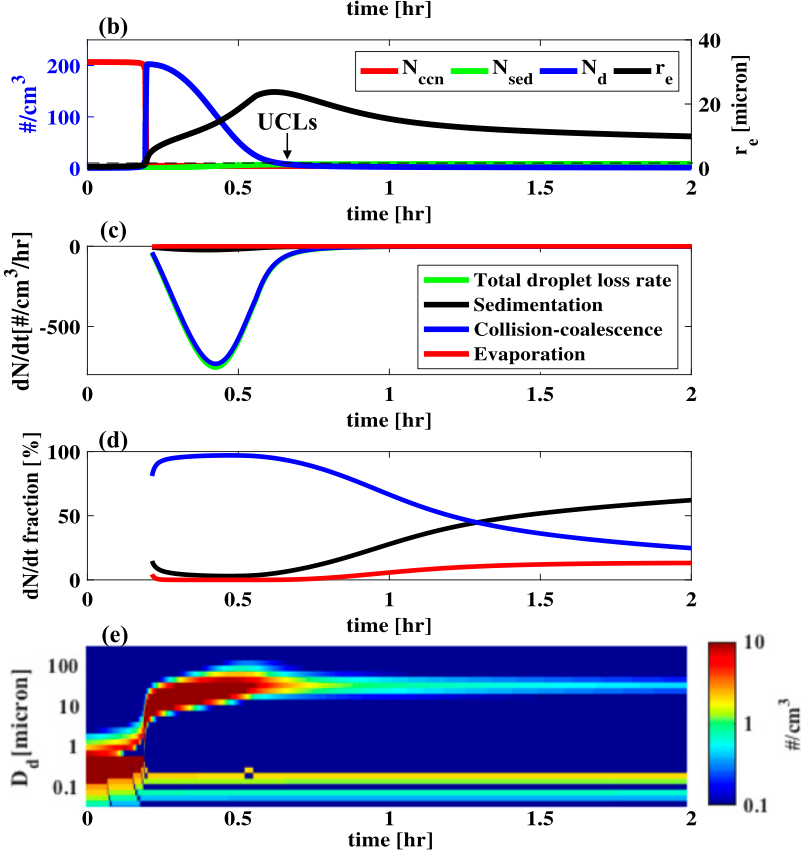

(f) Sc case with initial Nccn $=77 \mathrm{~cm}^{-3}$
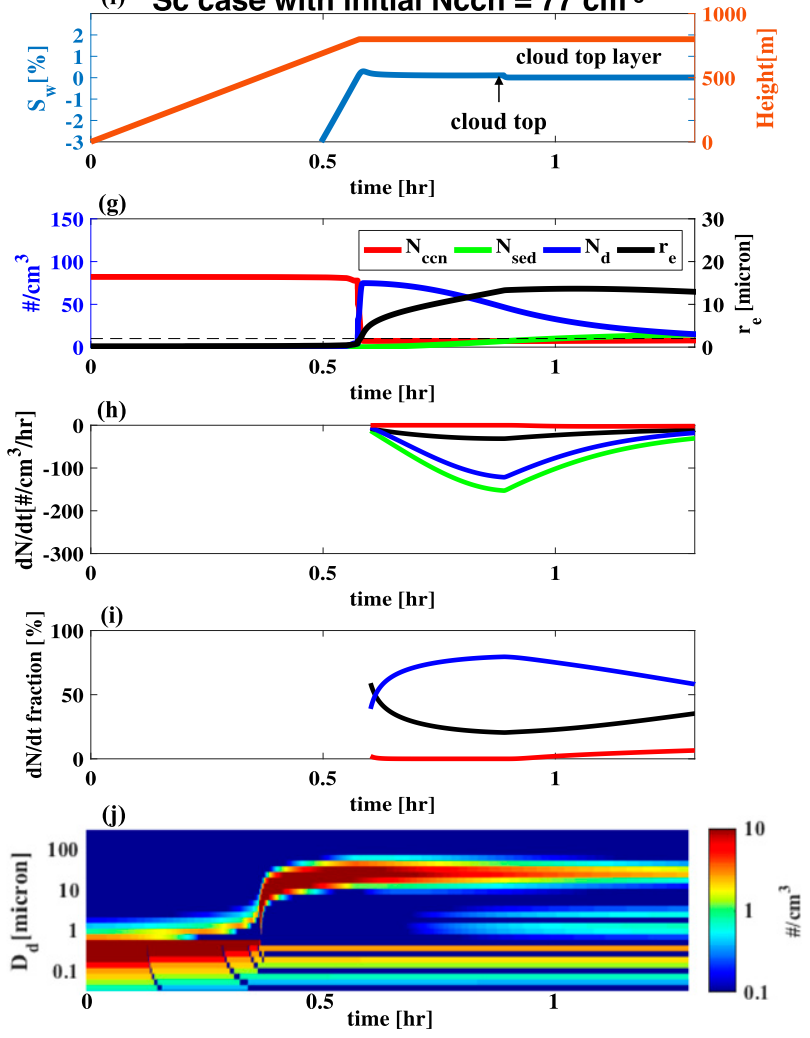

FIG. 11. Sensitivity tests to the initial $N_{\mathrm{ccn}}$ assumed in the $\mathrm{Cu}$ and $\mathrm{Sc}$ cases by the swapping initial aerosol condition in the $\mathrm{Cu}$ and $\mathrm{Sc}$ base cases. (a)-(e) Updraft $=0.75 \mathrm{~m} \mathrm{~s}^{-1}$, initial $N_{\text {ccn }}=207 \mathrm{~cm}^{-3}$, and cloud top $=1500 \mathrm{~m}$. (f)-(j) Updraft $=0.25 \mathrm{~m} \mathrm{~s}^{-1}$, initial $N_{\text {ccn }}=77 \mathrm{~cm}^{-3}$, and cloud top $=800 \mathrm{~m}$.

bulk form, which solve the prognostic equations only for the bulk parameters such as $N_{d}$ and $q_{L}$. Further, by using Eq. (2) and the parcel modeling, the time scale of droplet depletion and its dependence on $N_{d}$ and $q_{L}$ cannot be easily explored and examined. Thus, we use CSET observations to derive a parameterization for $\left[\dot{N}_{d}\right]_{\text {cs-SCE }}$ as a function of bulk parameters, which may provide more insight into the time scale of droplet depletion by collision-coalescence. In addition, with the parameterization of droplet coalescence-scavenging rate, we will explore the role of adiabaticity $f_{\text {ad }}$ in the collision-scavenging process. With the in situ measurements of DSDs [i.e., droplet size distribution from CDP and 2D cloud (2DC) probes of only the cloudy samples] from CSET (the details of the measurements used here and the criteria for choosing the cloudy samples are summarized in Part I), we fit the following formula to the droplet loss rate calculated from the SCE [Eq. (2)]:

$$
\left[\dot{N}_{d}\right]_{\text {cs-PARAM }}=-a\left(N_{d}\right)^{b}\left(q_{L}\right)^{c} .
$$

Note that units of $\left[\dot{N}_{d}\right]_{\text {cs-PARAM }}, N_{d}$, and $q_{L}$ in Eq. (3) are $\mathrm{m}^{-3} \mathrm{~s}^{-1}, \mathrm{~m}^{-3}$, and $\mathrm{kg} \mathrm{m}^{-3}$. The values of $a, b$, and $c$ from the best fitting are $8 \times 10^{4}\left(7 \times 10^{4}, 9 \times 10^{4}\right), 0.55$ $(0.545,0.555)$, and $1.37(1.36,1.375)$, where the values in parentheses are the lower and upper confidence bounds of the $95 \%$ confidence interval. Figure 12 shows the comparison of Eq. (3) with the values calculated by SCE, indicating that the bulk parameterization of Eq. (3) agrees fairly well with the SCE (correlation coefficient of 0.84 ). It should be noted that most of the bulk microphysics models divide condensate into cloud and rain and calculate the loss of $N_{d}$ in terms of the sum of autoconversion and accretion processes. The derived droplet loss rate from SCE [Eq. (2)] combines both of these effects and describes them in terms of a single $q_{L}$, which is simpler than one would use in a bulk parameterization and is useful for our purpose here. To further examine the accuracy of the parameterization, $\left[\dot{N}_{d}\right]_{\text {cs-BIN }}$ calculated from the bin microphysics parcel model (i.e., blue lines in Figs. 5c and 9c) can serve as the benchmark for the parameterized formula of Eq. (3).

Figures 13a and 13d show the temporal evolution of $N_{d}$ and $q_{L}$ calculated from the parcel model in the $\mathrm{Cu}$ and Sc base cases (same as Figs. 5 and 9). Note that in Fig. 13, $q_{L}$ [parcel] is the liquid water content of the cloud 
droplets inside the parcel, and $q_{L}$ [parcel + sedimentation] is $q_{L}$ [parcel] plus the liquid water content lost to sedimentation. In both cases, the comparison of adiabatic $q_{L}$ [calculated based on Eq. (19) from Pinsky et al. (2013)] with the output of $q_{L}$ from the parcel model (i.e., $q_{L}\left[N_{d}+\right.$ sedimentation]) shows good agreement, indicating that the mass of the condensate is well conserved in the modeled adiabatic rising parcel. With the outputs of $N_{d}$ and $q_{L}\left[N_{d}\right]$ from the parcel model, $\left[\dot{N}_{d}\right]_{\text {cs-PARAM }}$ can be calculated based on Eq. (3). Figures $13 \mathrm{~b}$ and $13 \mathrm{e}$ show the comparison of $\left[\dot{N}_{d}\right]_{\text {cs-PARAM }}$ with $\left[\dot{N}_{d}\right]_{\text {cs-BIN }}$ in the $\mathrm{Cu}$ and $\mathrm{Sc}$ base cases. The droplet loss rate calculated from the bin microphysics scheme and the parameterization are quite similar, suggesting that Eq. (3) could be a useful parameterization for $\left[\dot{N}_{d}\right]_{\mathrm{cs}}$.

The maximum $q_{L}$ in the $\mathrm{Cu}$ base case is 3 times as high as in the Sc base case because of the higher $z_{\text {top }}$ assigned in the $\mathrm{Cu}$ base case. Interestingly, as the product of $N_{d}$ and $q_{L}$, the values of $\left[\dot{N}_{d}\right]_{\text {cs }}$ are actually of the same order in two cases ( $N_{d}$ is higher in the Sc base case). Because the $\mathrm{Cu}$ and $\mathrm{Sc}$ base cases have different initial aerosol concentration assigned in the simulation, a better way to compare the efficiency of collision-coalescence is to use the fractional droplet loss rate given by

$$
\frac{\left[\dot{N}_{d}\right]_{\text {cs-PARAM }}}{N_{d}}=-8 \times 10^{4}\left(N_{d}\right)^{-0.45}\left(q_{L}\right)^{1.37} .
$$

Figures $13 \mathrm{c}$ and $13 \mathrm{f}$ show the fractional loss rate of droplets in the $\mathrm{Cu}$ and $\mathrm{Sc}$ cases. The results indicate that the maximum fractional loss rate in the Sc base case is nearly 5 times smaller than in the $\mathrm{Cu}$ base case. In the $\mathrm{Cu}$ base case, the fractional loss rate can be higher than $20 \% \mathrm{~min}^{-1}$. On the contrary, the maximum fractional loss rate in the Sc base case is lower than $5 \% \mathrm{~min}^{-1}$. Given that the initial aerosol concentration in the Sc base case is twice as large as in the $\mathrm{Cu}$ base case, this further illustrates that the formation of UCLs is very unfavorable in the Sc regime.

With Eq. (4), the exponential time scale of droplet depletion by collision-coalescence can be written as

$$
\tau_{\mathrm{cc}}[s]=\frac{\left(N_{d}\right)^{0.45}\left(q_{L}\right)^{-1.37}}{8 \times 10^{4}}
$$

Figure 14 shows $\tau_{\mathrm{cc}}$ calculated based on Eq. (5), indicating that the time scale of droplet depletion by collision-coalescence has strong dependence upon $q_{L}$ but weak dependence upon $N_{d}$. This finding is consistent with the modeling results presented in Feingold et al. (1996), which suggest that the fractional droplet depletion rate by collision-coalescence is a strongly convex function of $q_{L}$ and is almost independent of $N_{d}$ [see

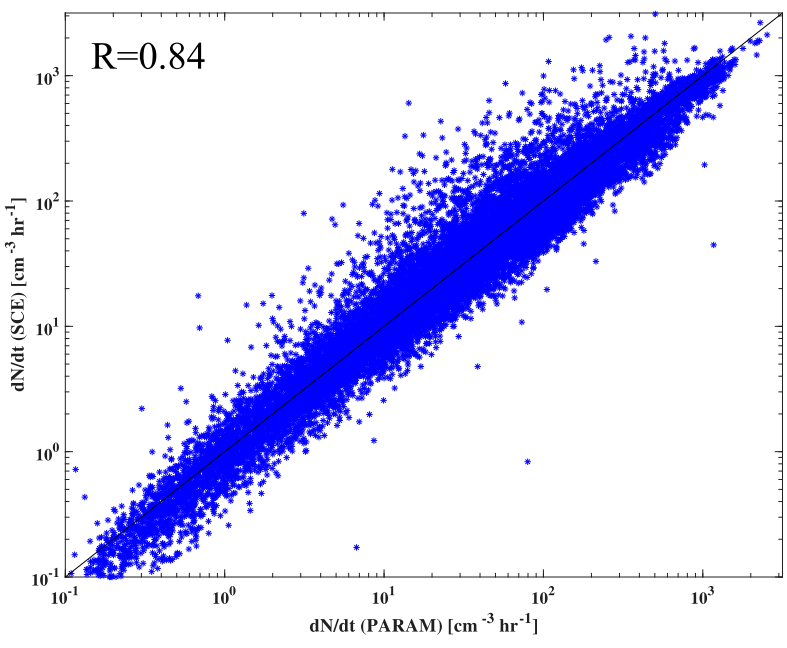

FIG. 12. Drop coalescence-scavenging rates estimated by integration of the SCE of Eq. (2) using observed DSDs from CSET against the parameterization given by Eq. (3). The collection kernel used here is described in section 2 .

Fig. 9 in Feingold et al. (1996)]. Because $q_{L}$ is proportional to the height above cloud base, it implies that the cloud-thickness $H_{t}$ is a more important factor constraining the coalescence-scavenging time scale in the MBL than is the aerosol concentration, as suggested in Wood [2006; see Eq. (18) in Wood (2006)].

\section{b. Fractional loss of droplets $f_{\text {top-loss }}$ and its dependence on $U_{z}, N_{d}, H_{t}$, and $f_{\mathrm{ad}}$}

In this section, we derive a simple formula from Eq. (3) relating $f_{\text {top-loss }}$ with $U_{z}, N_{d}, H_{t}$, and $f_{\text {ad }}$ in order to access the relative importance of different factors in the coalescence-scavenging process. By making an assumption that $q_{L}$ increases linearly with the height $z$ above cloud base, we can write

$$
q_{L}=f_{\mathrm{ad}} \Gamma_{\mathrm{ad}} z,
$$

where $\Gamma_{\mathrm{ad}}$ is the adiabatic rate of increase of liquid water content with respect to height and $f_{\text {ad }}$ is the degree of adiabaticity with the range between 0 and 1 . In stratocumulus, $f_{\text {ad }}$ is often observed to be close to unity, particularly for nondrizzling stratocumulus (Albrecht et al. 1990; Zuidema et al. 2005). However, in cumulus, $f_{\text {ad }}$ can be significantly lower because of entrainment and precipitation (Hobbs and Rangno 1996; Rauber et al. 2007). Several observational studies have shown that $f_{\text {ad }}$ typically decreases with increasing altitude in cumulus (Hobbs and Rangno 1996; Rauber et al. 2007). Wood et al. (2009) showed that observed $f_{\text {ad }}$ in cumulus can be parameterized by $z_{0} /\left(z_{0}+z\right)$, where $z_{0}$ is a scaling parameter, set to $500 \mathrm{~m}$. Our main purpose here is to derive a simple formula relating $f_{\text {top-loss }}$ with $U_{z}, N_{d}, H_{t}$, 

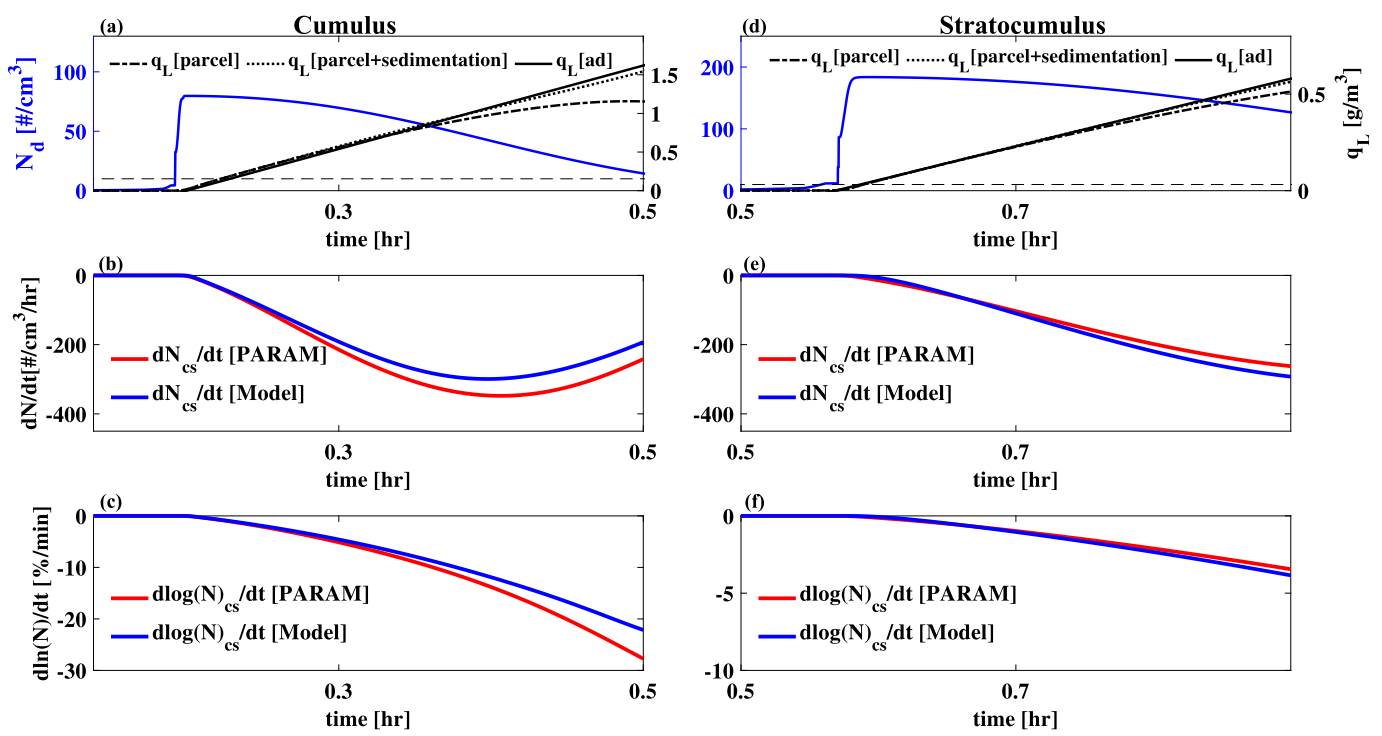

FIG. 13. Comparisons of the droplet coalescence-scavenging rates calculated based on the parameterization and the bin microphysics scheme. (a)-(c) The cumulus base case; (d)-(f) the stratocumulus base case. (a),(d) The temporal evolution of droplet concentration $N_{d}$ (blue), liquid water content inside the parcel $q_{L}$ [parcel] (black dot-dashed), liquid water content inside the parcel plus liquid water content lost to sedimentation $q_{L}$ [parcel + sedimentation] (black dotted), and adiabatic liquid water content $q_{L}$ [ad] (black solid); (b),(e) droplet coalescence-scavenging rates from the parameterization of Eq. (3) and the parcel model; (c),(f) fractional droplet coalescence-scavenging rates from the parameterization of Eq. (4) and the parcel model.

and $f_{\text {ad }}$, which is no longer possible if we retain the height dependence of $f_{\text {ad }}$ in the derivation. Therefore, in this study, we assume $f_{\text {ad }}$ is constant with height for simplicity. Also, $\Gamma_{\mathrm{ad}}$ is assumed to have a fixed value of $2.1 \mathrm{~g} \mathrm{~m}^{-3} \mathrm{~km}^{-1}$, which is typical for the MBL clouds in the subtropics and tropics (Albrecht et al. 1990). With Eq. (6), integrated liquid water path from the cloud base to $z$ can be written as

$$
\operatorname{LWP}(z)=\frac{f_{\mathrm{ad}} \Gamma_{\mathrm{ad}} z^{2}}{2}
$$

By substituting $q_{L}$ from Eq. (6) into Eq. (3) and dividing Eq. (3) by $U_{z}$, the decrease in $N_{d}$ with increasing altitude can be given by

$$
\frac{d N_{d}}{d z}=\frac{-a\left(N_{d}\right)^{0.55}\left(f_{\mathrm{ad}} \Gamma_{\mathrm{ad}} z\right)^{1.37}}{U_{z}} .
$$

The integration of Eq. (8) yields

$$
\frac{\left(N_{d}\right)_{z}^{0.45}-\left(N_{d}\right)_{\mathrm{base}}^{0.45}}{0.45}=\frac{-a\left(f_{\mathrm{ad}} \Gamma_{\mathrm{ad}}\right)^{1.37} z^{2.37}}{2.37 U_{z}},
$$

where $\left(N_{d}\right)_{z}$ is the number concentration of droplets at the altitude $z$ and $\left(N_{d}\right)_{\text {base }}$ is the number concentration of droplets activated at the cloud base. Then, by Eq. (9), the fractional loss of $N_{d}$ from the cloud base to the cloud top $f_{\text {top-loss }}$ by collision-coalescence can be given by

$$
\begin{aligned}
f_{\text {top-loss }} & =1-\frac{\left(N_{d}\right)_{\text {top }}}{\left(N_{d}\right)_{\text {base }}}=1-\left(1-\chi_{\mathrm{cc}}\right)^{2.2} \\
\chi_{\mathrm{cc}} & =k \frac{\left(f_{\mathrm{ad}}\right)^{1.37} H_{t}^{2.37}}{\left(N_{d}\right)_{\text {base }}^{0.45} U_{z}} \\
k & =0.19 a\left(\Gamma_{\mathrm{ad}}\right)^{1.37}
\end{aligned}
$$

where $\left(N_{d}\right)_{\text {top }}$ is the droplet concentration at the cloud top and $\chi_{\mathrm{cc}}$ is termed the collision-coalescence efficiency factor. The expression in Eq. (10) shows that $f_{\text {top-loss }}$ increases with the increase in $f_{\text {ad }}$ and $H_{t}$ but decreases with the increase in $U_{z}$ and $\left(N_{d}\right)_{\text {base }}$. The positive correlation of $f_{\text {top-loss }}$ with $f_{\text {ad }}$ and $H_{t}$ is straightforward. The droplet coalescence-scavenging rate is strongly dependent on $q_{L}$ (see section 4a), so higher adiabaticity and deeper cloud depth (i.e., higher LWP) both increase the depletion of $N_{d}$ through collision-coalescence. Regarding the negative correlation of $f_{\text {top-loss }}$ with $U_{z}$ and $\left(N_{d}\right)_{\text {base }}$, the illustration is already given in sections 3 and $4 a$. Figure 14 shows contour plots of $f_{\text {top-loss }}$ against $U_{z}, N_{d}, H_{t}$, and $f_{\text {ad }}$ by assuming a reference $U_{z}=1 \mathrm{~m} \mathrm{~s}^{-1},\left(N_{d}\right)$ base $=75 \mathrm{~cm}^{-3}, H_{t}=1000 \mathrm{~m}$, and $f_{\text {ad }}=0.6$. These values are used when they are not the variables in the contour plots (e.g., $U_{z}=1 \mathrm{~m} \mathrm{~s}^{-1}$ and 


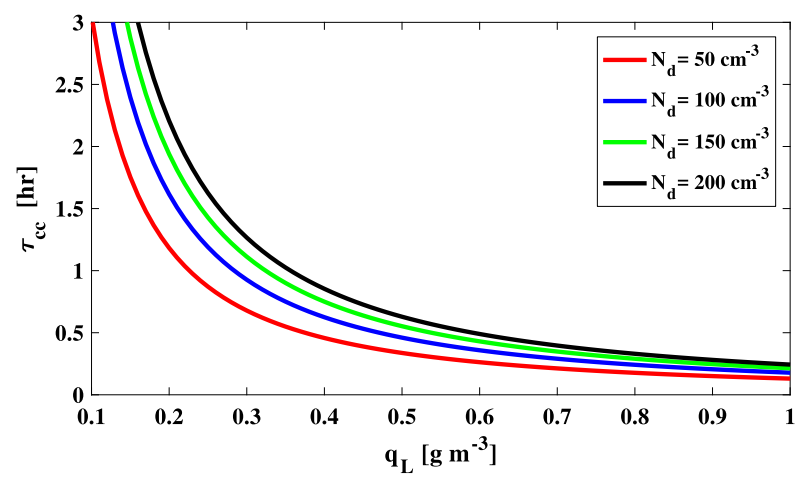

FIG. 14. Time scale of droplet loss by collision-coalescence calculated by Eq. (5) as a function of liquid water content.

$f_{\text {ad }}=0.6$ are assumed in Fig. 15a). To explore the sensitivity to the assumed reference values, another set of reference values is used [i.e., $U_{z}=0.25 \mathrm{~m} \mathrm{~s}^{-1},\left(N_{d}\right)_{\text {base }}=$ $200 \mathrm{~cm}^{-3}, H_{t}=300 \mathrm{~m}$, and $\left.f_{\mathrm{ad}}=1\right]$, and the results are shown in Fig. 16. The results calculated using two different sets of reference values are qualitatively very similar, which indicate that $H_{t}$ is the most dominant factor determining $f_{\text {top-loss }}$, and $f_{\text {top-loss }}$ is found to be very insensitive to $\left(N_{d}\right)_{\text {base }}$. We found that $U_{z}$ is found to play a more important role in determining $f_{\text {top-loss }}$ than does $f_{\text {ad }}$. Overall, the relative importance of these factors determining the fraction loss of droplets in the updraft can be summarized as $H_{t}>U_{z}>f_{\text {ad }}>\left(N_{d}\right)_{\text {base }}$. This finding implies that $H_{t}$ is a critical factor governing the efficiency of the coalescence-scavenging process. It should be noted that the order of importance of the factors discussed in this section is for the fraction loss in the updraft $f_{\text {top-loss, }}$, which is different from the indicator for the UCLs, the actual absolute number of droplets and aerosols $\left(<10 \mathrm{~cm}^{-3}\right)$. However, the discussion here gives an important implication for the UCLs such that the formation of UCLs could be strongly susceptible to the variability of cloud thickness, which will be the focus of a future study.

\section{c. Effect of parcel cycling on droplet depletion in stratocumulus}

Air parcels in stratocumulus could cycle more than one time, and multiple cycles through cloud could have an effect on depletion of aerosol concentration and the associated potential to produce UCLs. The parameterization of droplet fraction loss in the updraft through collision-coalescence [i.e., Eq. (10)] is a useful tool to address this question. In the typical $\mathrm{Sc}$ regime, the background aerosol concentration $N_{\mathrm{ccn}}$ in the surface mixed layer ranges from $200 \mathrm{~cm}^{-3}$ (CSET; see section 2c for details) to $>400 \mathrm{~cm}^{-3}$ [VAMOS Ocean-CloudAtmosphere-Land Study (VOCALS); southeastern Pacific; see Allen et al. 2011). A recent model study
(Chen et al. 2016) suggested that the number concentration of activated droplet is approximately equal to the initial $N_{\text {ccn }}$ in the Sc regime. Here, we simply assumed that the typical initial activated $N_{d}$ (i.e., before first parcel cycling) in the $\mathrm{Sc}$ regime is $300 \mathrm{~cm}^{-3}$. Based on Eq. (10), fraction loss of $N_{d}$ after one parcel cycling (i.e., $f_{\text {top-loss }}$ ) in the $\mathrm{Sc}$ regime (i.e., cloud thickness $=300 \mathrm{~m}$, updraft $=0.25 \mathrm{~m} \mathrm{~s}^{-1}$ ) is approximately $30 \%$ (see Fig. 16a). Note that the dependence of $f_{\text {top-loss }}$ on $N_{d}$ is relatively small and is neglected in the discussion here. If there is no new aerosol source while parcel cycling, then the number of parcel cycling required for the formation of UCLs in the Sc regime would be 10 (i.e., $300 \mathrm{~cm}^{-3} \times$ $\left.0.7^{10}=8.4 \mathrm{~cm}^{-3}\right)$. This indicates that a relatively large number of cycles through cloud is necessary for the formation of UCLs in the typical Sc regime as opposed to the $\mathrm{Cu}$ regime, where only one parcel cycle is needed, as shown in section 3 . We should also note that a large number of cloud cycles also implies more possibility for aerosol entrainment, which could suppress the formation of UCLs. By using in situ aircraft observations, Terai et al. (2014) found that the POCs of stratocumulus clouds are typically aerosol-depleted UCLs. Based on the discussion given here, we postulate that formation of POCs is strongly associated with aerosol depletion that results from multiple cycles of air through a stratocumulus cloud, a hypothesis that is worthy of investigation in future modeling studies.

\section{Conclusions}

In Part I, based on the aircraft measurements from CSET, we found that ultraclean layers (UCLs) are common features in the SCT region over the northeastern subtropical Pacific Ocean and their fractional coverage can exceed $\sim 50 \%$ where the PBL height exceeds $1 \mathrm{~km}$. In this paper, the main goal is to test a hypothesis for the formation of UCLs in the MBL, namely, that the deep PBL height over the SCT region can provide high $q_{L}$ in the active $\mathrm{Cu}$ for collisioncoalescence to sufficiently deplete $N_{d}$, resulting in low $N_{d}$ and large $r_{e}$ in clouds that are frequently observed in the upper MBL over the SCT region. Because of the efficient coalescence-scavenging process, after the evaporation of UCL clouds, only a few accumulation mode particles are returned to the clear sky, leaving very low $N_{\text {ccn }}$ in the upper MBL.

A rising adiabatic parcel model with a 2D bin microphysics scheme is formulated to test the hypothesis. The results suggest that in the cumulus regime, collisioncoalescence can efficiently deplete $N_{d}$, grow droplets, and remove $N_{\mathrm{ccn}}$ from the atmosphere in Cu updrafts, leading to the occurrence of UCLs in the upper MBL. In 
(a)

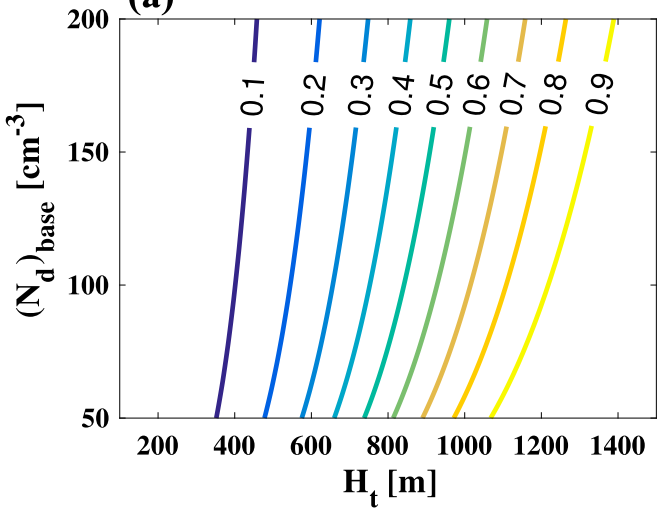

(b)

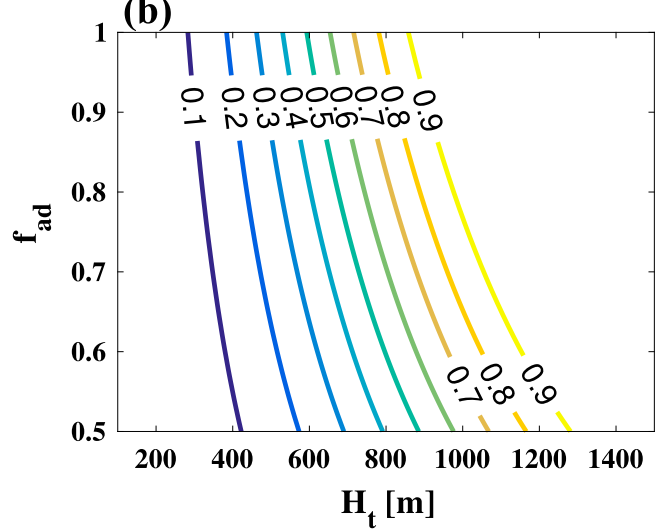

(c)

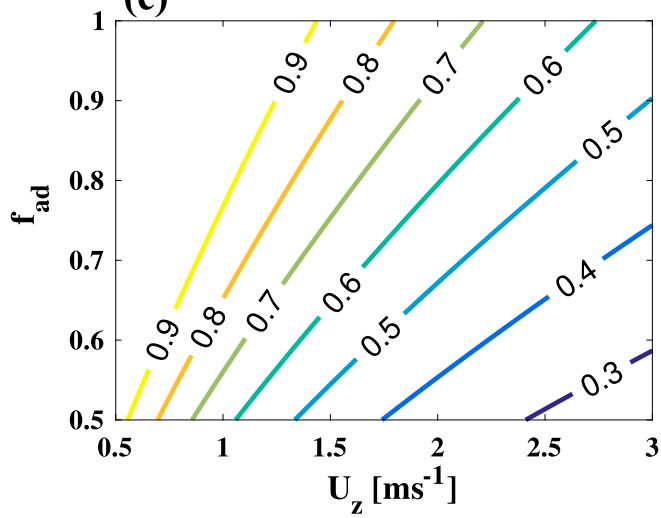

(d)
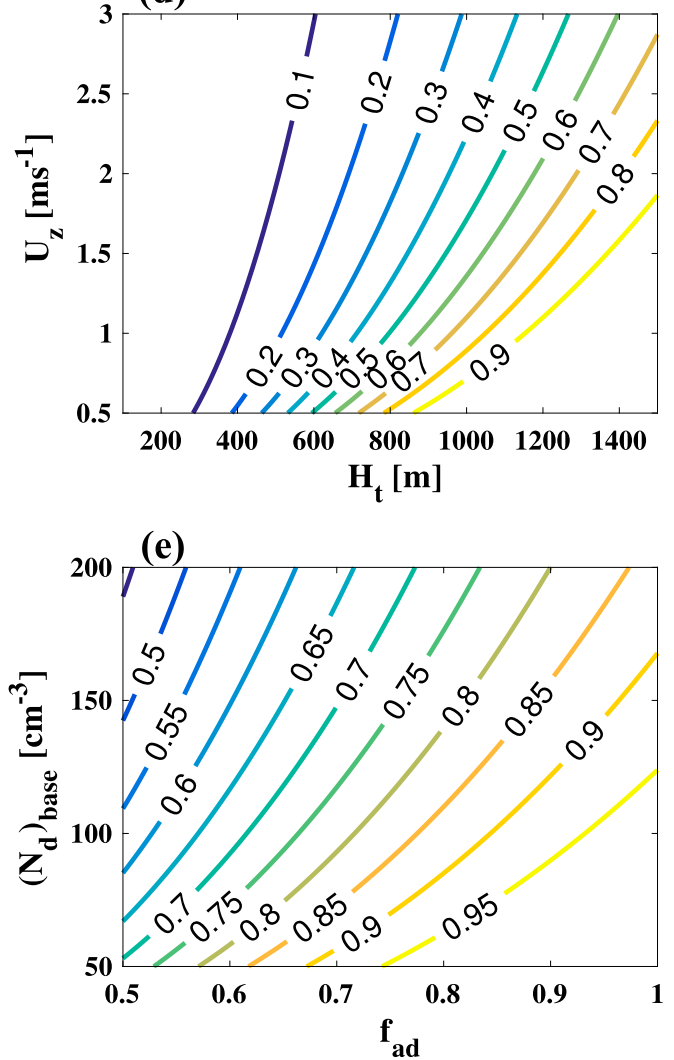

(f)

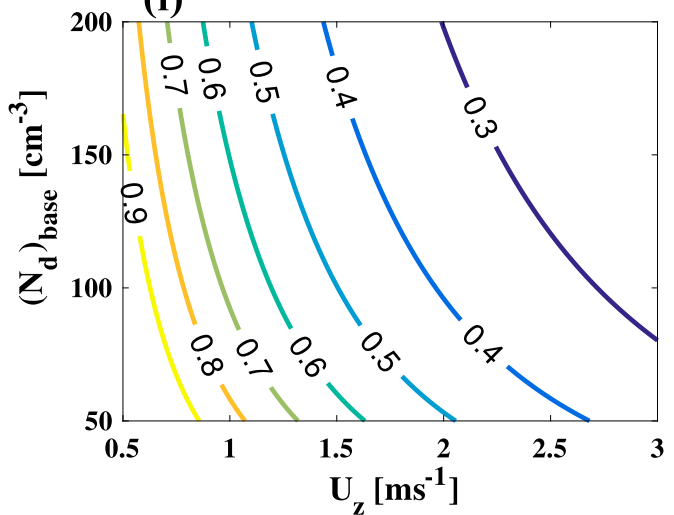

FIG. 15. Contour plots of fractional loss of $N_{d}$ at the cloud top from the cloud base $f_{\text {top-loss }}$ and its dependence on $U_{z},\left(N_{d}\right)_{\text {base }}, H_{t}$, and $f_{\text {ad }}$ calculated using Eq. (10). A reference $U_{z}=1 \mathrm{~m} \mathrm{~s}^{-1},\left(N_{d}\right)_{\text {base }}=75 \mathrm{~cm}^{-3}, H_{t}=1000 \mathrm{~m}$, and $f_{\text {ad }}=0.6$ are assumed when they are not the variables in the plot [e.g., (a) $U_{z}=1 \mathrm{~m} \mathrm{~s}^{-1}$ and $f_{\text {ad }}=0.6$ are assumed].

Part I, a case study with the geostationary satellite data has revealed that the UCL clouds are often associated with considerable amount of optically thin MBL clouds $(\tau<0.3)$. We postulate that the observed optically thin clouds are often layers detraining from the active $\mathrm{Cu}$ towers in the upper MBL. The shallow depth and low $N_{d}$ in these cloudy detrainment layers both contribute to the observed low cloud optical depth. The maintenance of these optically thin cloudy detrainment layers involves a balance between radiation, mesoscale ascent, and cloud microphysics, which is certainly important but beyond the scope of our current paper. We leave that for a future LES study. On the other hand, the parcel modeling suggests that the formation of UCLs is typically not favored in the $\mathrm{Sc}$ regime as compared to the $\mathrm{Cu}$ regime. In summary, the idealized cloud parcel simulation 
(a)

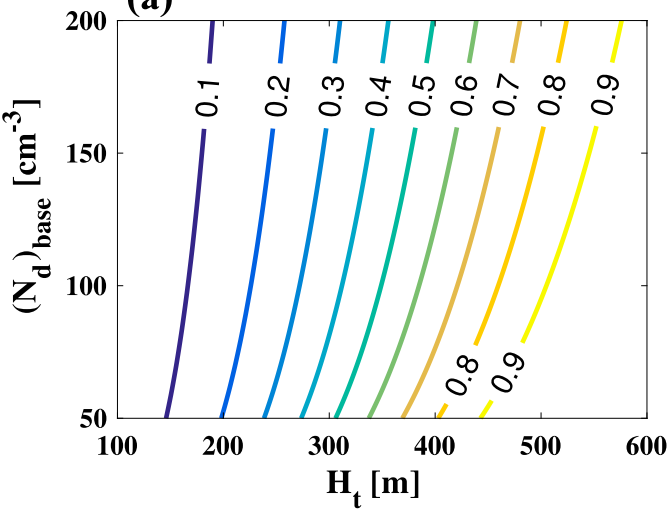

(b)

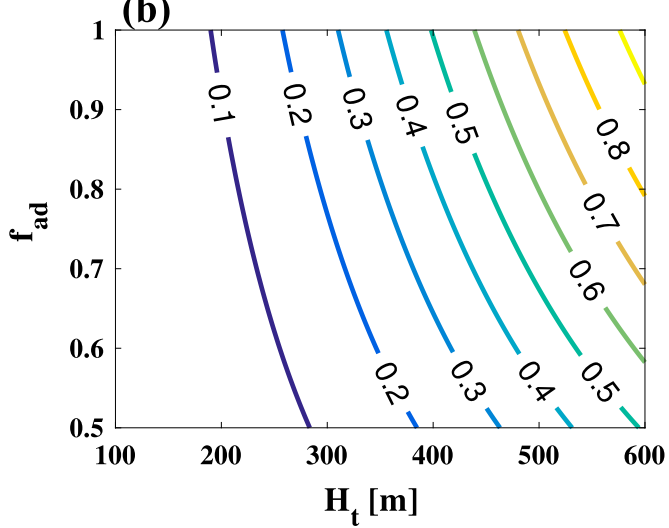

(c)

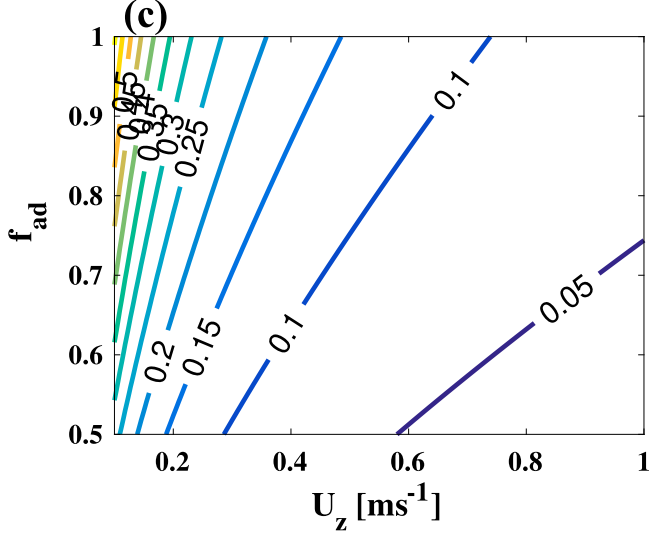

(d)

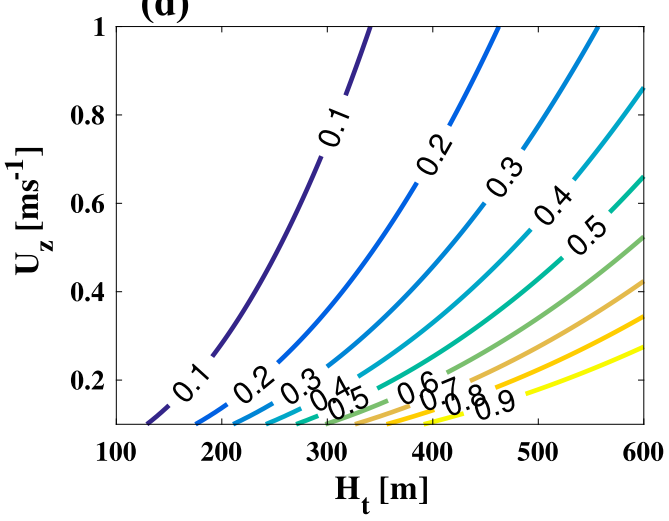

(e)

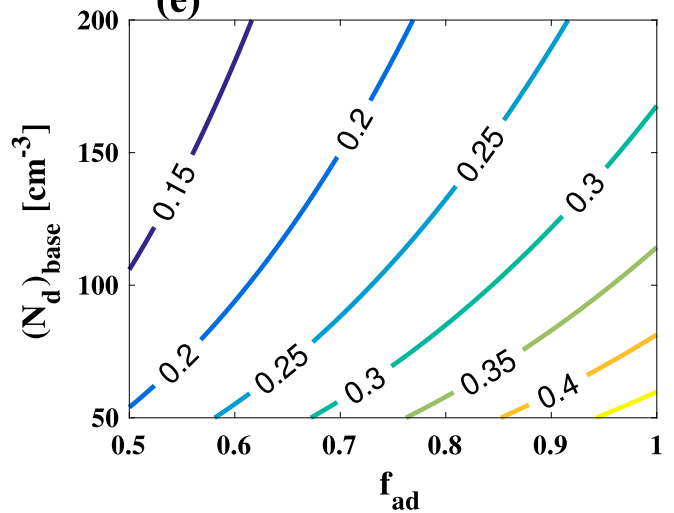

(f)

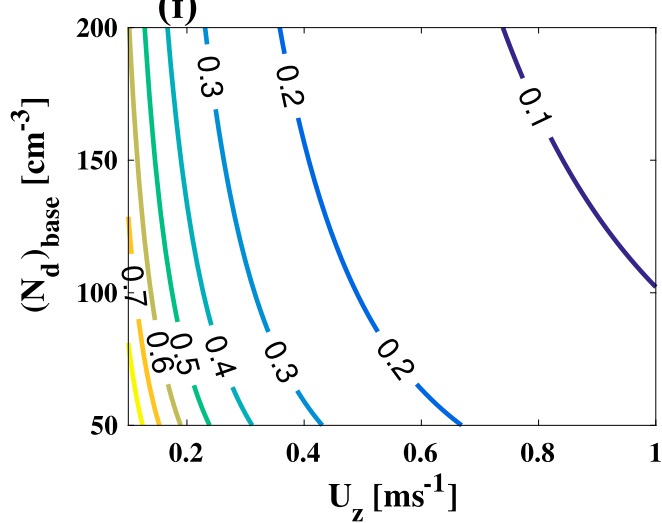

FIG. 16. As in Fig. 15, but a reference $U_{z}=0.25 \mathrm{~m} \mathrm{~s}^{-1},\left(N_{d}\right)_{\text {base }}=200 \mathrm{~cm}^{-3}, H_{t}=300 \mathrm{~m}$, and $f_{\text {ad }}=1$ are assumed when they are not the variables in the plot [e.g., (a) $U_{z}=0.25 \mathrm{~m} \mathrm{~s}^{-1}$ and $f_{\text {ad }}=1$ are assumed].

in this work is able to explain the observed sharp rise of UCL coverage in the SCT region.

A parameterized expression for the droplet coalescence-scavenging rate $\left[\dot{N}_{d}\right]_{\text {cs-PARAM }}$ is derived as a function of bulk parameters $N_{d}$ and $q_{L}$ based on the in situ measurements of DSDs from CSET. The comparison of $\left[\dot{N}_{d}\right]_{\text {cs-PARAM }}$ with the droplet loss rate derived from the SCE and the bin microphysics parcel model generally shows good agreement, suggesting that
$\left[\dot{N}_{d}\right]_{\text {cs-PARAM }}$ is a useful parameterization. The derived parameters in $\left[\dot{N}_{d}\right]_{\text {cs-PARAM }}$ imply that the time scale of droplet depletion by collision-coalescence is strongly dependent upon $q_{L}$ but is weakly dependent upon $N_{d}$. An expression for the fractional droplet loss from the cloud base to the cloud top $f_{\text {top-loss }}$ by collisioncoalescence is formulated as a function of a collisioncoalescence efficiency factor $\chi_{\mathrm{cc}}$ that depends on the cloud-layer thickness, adiabaticity, updraft velocity, and 
cloud-base droplet concentration. Of these factors, cloud thickness is the most dominant factor determining $f_{\text {top-loss }}$, and such finding is consistent with the results presented in Feingold et al. (1996) and Wood (2006). In the SCT region, the variation of cloud thickness is controlled mainly by cloud-top height (i.e., cloud-base heights do not vary as much as cloud-top heights), which is constrained by PBL height. The implication is that PBL depth could play a crucial role governing the temporal and spatial variation of $N_{d}$ and thus UCLs in the transition region, an issue that will be thoroughly explored in future work.

Acknowledgments. We appreciate the constructive suggestions and comments from three anonymous reviewers that helped to improve this paper. This research was supported by NSF Cloud System Evolution in the Trades (CSET) project (AGS-1445813). We thank Marcia Baker and Jørgen Jensen for helpful discussion.

\section{REFERENCES}

Ackerman, A. S., M. P. Kirkpatrick, D. E. Stevens, and O. B. Toon, 2004: The impact of humidity above stratiform clouds on indirect aerosol climate forcing. Nature, 432, 1014-1017, https:// doi.org/10.1038/nature03174

Albrecht, B. A., 1989: Aerosols, cloud microphysics, and fractional cloudiness. Science, 245, 1227-1230, https://doi.org/10.1126/ science.245.4923.1227.

, C. W. Fairall, D. W. Thomson, A. B. White, J. B. Snider, and W. H. Schubert, 1990: Surface-based remote sensing of the observed and the adiabatic liquid water content of stratocumulus clouds. Geophys. Res. Lett., 17, 89-92, https://doi.org/ 10.1029/GL017i001p00089.

Allen, G., and Coauthors, 2011: South east Pacific atmospheric composition and variability sampled along $20^{\circ} \mathrm{S}$ during VOCALS-REx. Atmos. Chem. Phys., 11, 5237-5262, https:// doi.org/10.5194/acp-11-5237-2011.

Berner, A. H., C. S. Bretherton, R. Wood, and A. Muhlbauer, 2013: Marine boundary layer cloud regimes and POC formation in a CRM coupled to a bulk aerosol scheme. Atmos. Chem. Phys., 13, 12 549-12 572, https://doi.org/10.5194/acp-13-12549-2013

Boers, R., and P. B. Krummel, 1998: Microphysical properties of boundary layer clouds over the Southern Ocean during ACE 1. J. Geophys. Res., 103, 16 651-16 663, https://doi.org/10.1029/ 97JD03280

- J. B. Jensen, P. B. Krummel, and H. Gerber, 1996: Microphysical and short-wave radiative structure of wintertime stratocumulus clouds over the Southern Ocean. Quart. J. Roy. Meteor. Soc., 122, 1307-1339, https://doi.org/10.1002/ qj. 49712253405 .

Bott, A., 1998: A flux method for the numerical solution of the stochastic collection equation. J. Atmos. Sci., 55, 2284-2293, https:// doi.org/10.1175/1520-0469(1998)055<2284:AFMFTN >2.0.CO;2. , 2000: A flux method for the numerical solution of the stochastic collection equation: Extension to two-dimensional particle distributions. J. Atmos. Sci., 57, 284-294, https://doi. org/10.1175/1520-0469(2000)057<0284:AFMFTN>2.0.CO;2.
Bretherton, C. S., and Coauthors, 2004: The EPIC 2001 stratocumulus study. Bull. Amer. Meteor. Soc., 85, 967-978, https:// doi.org/10.1175/BAMS-85-7-967.

— P. N. Blossey, and J. Uchida, 2007: Cloud droplet sedimentation, entrainment efficiency, and subtropical stratocumulus albedo. Geophys. Res. Lett., 34, L03813, https://doi.org/ 10.1029/2006GL027648.

Celik, F., and J. D. Marwitz, 1999: Droplet spectra broadening by ripening process. Part I: Roles of curvature and salinity of cloud droplets. J. Atmos. Sci., 56, 3091-3105, https://doi.org/ 10.1175/1520-0469(1999)056<3091:DSBBRP > 2.0.CO;2.

Chen, J., Y. Liu, M. Zhang, and Y. Peng, 2016: New understanding and quantification of the regime dependence of aerosol-cloud interaction for studying aerosol indirect effects. Geophys. Res. Lett., 43, 1780-1787, https://doi.org/10.1002/2016GL067683.

Chen, J.-P., and D. Lamb, 1994: Simulation of cloud microphysical and chemical processes using a multicomponent framework. Part I: Description of the microphysical model. J. Atmos. Sci., 51, 2613-2630, https://doi.org/10.1175/15200469(1994)051<2613:SOCMAC $>2.0$. CO;2.

Clarke, A. D., S. R. Owens, and J. Zhou, 2006: An ultrafine sea-salt flux from breaking waves: Implications for cloud condensation nuclei in the remote marine atmosphere. J. Geophys. Res., 111, D06202, https://doi.org/10.1029/2005JD006565.

Comstock, K. K., S. E. Yuter, R. Wood, and C. S. Bretherton, 2007: The three-dimensional structure and kinematics of drizzling stratocumulus. Mon. Wea. Rev., 135, 3767-3784, https:// doi.org/10.1175/2007MWR1944.1.

Eastman, R., R. Wood, and K. T. O, 2017: The subtropical stratocumulus-topped planetary boundary layer: A climatology and the Lagrangian evolution. J. Atmos. Sci., 74, 26332656, https://doi.org/10.1175/JAS-D-16-0336.1.

Feingold, G., and H. Siebert, 2009: Cloud-aerosol interactions from the micro to the cloud scale. Clouds in the Perturbed Climate System: Their Relationship to Energy Balance, Atmospheric Dynamics, and Precipitation, J. Heintzenberg and R. Charlson, Eds., MIT Press, 319-338, https://doi.org/10.7551/ mitpress/9780262012874.003.0014.

, S. M. Kreidenweis, B. Stevens, and W. R. Cotton, 1996: Numerical simulations of stratocumulus processing of cloud condensation nuclei through collision-coalescence. J. Geophys. Res., 101, 21 391-21 402, https://doi.org/10.1029/ 96JD01552.

Ferek, R. J., and Coauthors, 2000: Drizzle suppression in ship tracks. J. Atmos. Sci., 57, 2707-2728, https://doi.org/10.1175/ 1520-0469(2000)057<2707:DSIST >2.0.CO;2.

Gerber, H. E., G. M. Frick, J. B. Jensen, and J. G. Hudson, 2008: Entrainment, mixing, and microphysics in trade-wind cumulus. J. Meteor. Soc. Japan, 86, 87-106, https://doi.org/10.2151/ jmsj.86A.87.

Ghate, V. P., M. A. Miller, and L. DiPretore, 2011: Vertical velocity structure of marine boundary layer trade wind cumulus clouds. J. Geophys. Res., 116, D16206, https://doi.org/10.1029/ 2010JD015344.

Gultepe, I., and G. A. Isaac, 2004: Aircraft observations of cloud droplet number concentration: Implications for climate studies. Quart. J. Roy. Meteor. Soc., 130, 2377-2390, https://doi.org/ 10.1256/qj.03.120.

Hall, W. D., 1980: A detailed microphysical model within a twodimensional dynamic framework: Model description and preliminary results. J. Atmos. Sci., 37, 2486-2507, https://doi.org/ 10.1175/1520-0469(1980)037<2486:ADMMWA>2.0.CO;2. 
Hobbs, P. V., and A. L. Rangno, 1996: Precipitation from a maritime cloud layer with very low droplet concentrations. Atmos. Res., 40, 99-107, https://doi.org/10.1016/0169-8095(95)00030-5.

Houze, R. A., Jr., 2014: Cloud Dynamics. Academic Press, 432 pp.

Hudson, J. G., 1993: Cloud condensation nuclei near marine cumulus. J. Geophys. Res., 98, 2693-2702, https://doi.org/ 10.1029/92JD02169.

_- and P. R. Frisbie, 1991: Cloud condensation nuclei near marine stratus. J. Geophys. Res., 96, 20 795-20 808, https:// doi.org/10.1029/91JD02212.

_ , and H. Li, 1995: Microphysical contrasts in Atlantic stratus. J. Atmos. Sci., 52, 3031-3040, https://doi.org/10.1175/15200469(1995)052<3031:MCIAS > 2.0.CO;2.

Jung, E., B. A. Albrecht, A. Sorooshian, P. Zuidema, and H. H. Jonsson, 2016: Precipitation susceptibility in marine stratocumulus and shallow cumulus from airborne measurements. Atmos. Chem. Phys., 16, 11395-11413, https://doi.org/ 10.5194/acp-16-11395-2016.

Kogan, Y. L., 2006: Large-eddy simulation of air parcels in stratocumulus clouds: Time scales and spatial variability. J. Atmos. Sci., 63, 952-967, https://doi.org/10.1175/JAS3665.1.

Korolev, A. V., and I. P. Mazin, 2003: Supersaturation of water vapor in clouds. J. Atmos. Sci., 60, 2957-2974, https://doi.org/ 10.1175/1520-0469(2003)060<2957:SOWVIC >2.0.CO;2.

Lee, S.-S., G. Feingold, and P. Y. Chuang, 2012: Effect of aerosol on cloud-environment interactions in trade cumulus. J. Atmos. Sci., 69, 3607-3632, https://doi.org/10.1175/JAS-D12-026.1.

Lu, M.-L., W. C. Conant, H. H. Jonsson, V. Varutbangkul, R. C. Flagan, and J. H. Seinfeld, 2007: The Marine Stratus/Stratocumulus Experiment (MASE): Aerosol-cloud relationships in marine stratocumulus. J. Geophys. Res., 112, D10209, https:// doi.org/10.1029/2006JD007985.

Ovchinnikov, M., R. C. Easter, and W. I. Gustafson, 2013: Untangling dynamical and microphysical controls for the structure of stratocumulus. Geophys. Res. Lett., 40, 4432-4436, https://doi.org/10.1002/grl.50810.

Petters, M., and S. Kreidenweis, 2007: A single parameter representation of hygroscopic growth and cloud condensation nucleus activity. Atmos. Chem. Phys., 7, 1961-1971, https://doi. org/10.5194/acp-7-1961-2007.

Pinsky, M., I. Mazin, A. Korolev, and A. Khain, 2013: Supersaturation and diffusional droplet growth in liquid clouds. J. Atmos. Sci., 70, 2778-2793, https://doi.org/10.1175/JAS-D-12-077.1.

$-, \ldots,-$, and -2014 : Supersaturation and diffusional droplet growth in liquid clouds: Polydisperse spectra. J. Geophys. Res. Atmos., 119, 12 872-12 887, https://doi.org/ 10.1002/2014JD021885.

Pringle, K., H. Tost, A. Pozzer, U. Pöschl, and J. Lelieveld, 2010: Global distribution of the effective aerosol hygroscopicity parameter for CCN activation. Atmos. Chem. Phys., 10, 52415255, https://doi.org/10.5194/acp-10-5241-2010.

Pruppacher, H. R., and J. D. Klett, 2012: Microphysics of Clouds and Precipitation. Springer Science and Business Media, 714 pp.

Rauber, R. M., and Coauthors, 2007: Rain in shallow cumulus over the ocean: The RICO campaign. Bull. Amer. Meteor. Soc., 88, 1912-1928, https://doi.org/10.1175/BAMS-88-12-1912.

Rogers, R. R., and M. Yau, 1989: A Short Course in Cloud Physics. International Series in Natural Philosophy, Butterworth Heinemann, 304 pp.

Sharon, T. M., B. A. Albrecht, H. H. Jonsson, P. Minnis, M. M. Khaiyer, T. M. van Reken, J. Seinfeld, and R. Flagan, 2006: Aerosol and cloud microphysical characteristics of rifts and gradients in maritime stratocumulus clouds. J. Atmos. Sci., 63 , 983-997, https://doi.org/10.1175/JAS3667.1.

Small, J. D., P. Y. Chuang, G. Feingold, and H. Jiang, 2009: Can aerosol decrease cloud lifetime? Geophys. Res. Lett., 36, L16806, https://doi.org/10.1029/2009GL038888.

Sorooshian, A., G. Feingold, M. D. Lebsock, H. Jiang, and G. L. Stephens, 2009: On the precipitation susceptibility of clouds to aerosol perturbations. Geophys. Res. Lett., 36, L13803, https:// doi.org/10.1029/2009GL038993.

Squires, P., 1958: The spatial variation of liquid water and droplet concentration in cumuli. Tellus, 10A, 372-380, https://doi.org/ 10.3402/tellusa.v10i3.9244.

Stephens, G. L., and C. M. R. Platt, 1987: Aircraft observations of the radiative and microphysical properties of stratocumulus and cumulus cloud fields. J. Climate Appl. Meteor., 26, 1243-1269, https:// doi.org/10.1175/1520-0450(1987)026<1243:AOOTRA > 2.0.CO;2.

Terai, C. R., R. Wood, D. Leon, and P. Zuidema, 2012: Does precipitation susceptibility vary with increasing cloud thickness in marine stratocumulus? Atmos. Chem. Phys., 12, 45674583, https://doi.org/10.5194/acp-12-4567-2012.

_ C. S. Bretherton, R. Wood, and G. Painter, 2014: Aircraft observations of aerosol, cloud, precipitation, and boundary layer properties in pockets of open cells over the southeast Pacific. Atmos. Chem. Phys., 14, 8071-8088, https://doi.org/ 10.5194/acp-14-8071-2014.

_, R. Wood, and T. Kubar, 2015: Satellite estimates of precipitation susceptibility in low-level marine stratiform clouds. J. Geophys. Res. Atmos., 120, 8878-8889, https://doi.org/ 10.1002/2015JD023319.

Twomey, S., 1977: The influence of pollution on the shortwave albedo of clouds. J. Atmos. Sci., 34, 1149-1152, https://doi.org/ 10.1175/1520-0469(1977)034<1149:TIOPOT>2.0.CO;2.

Weickmann, H., and H. Aufm Kampe, 1953: Physical properties of cumulus clouds. J. Meteor., 10, 204-211, https://doi.org/ 10.1175/1520-0469(1953)010<0204:PPOCC > 2.0.CO;2.

Wood, R., 2005: Drizzle in stratiform boundary layer clouds. Part II: Microphysical aspects. J. Atmos. Sci., 62, 3034-3050, https:// doi.org/10.1175/JAS3530.1.

_ 2006: Rate of loss of cloud droplets by coalescence in warm clouds. J. Geophys. Res., 111, D21205, https://doi.org/10.1029/ 2006JD007553.

- 2007: Cancellation of aerosol indirect effects in marine stratocumulus through cloud thinning. J. Atmos. Sci., 64, 26572669, https://doi.org/10.1175/JAS3942.1.

- S. Irons, and P. Jonas, 2002: How important is the spectral ripening effect in stratiform boundary layer clouds? Studies using simple trajectory analysis. J. Atmos. Sci., 59, 2681-2693, https:// doi.org/10.1175/1520-0469(2002)059<2681:HIITSR > 2.0.CO;2.

—, T. L. Kubar, and D. L. Hartmann, 2009: Understanding the importance of microphysics and macrophysics for warm rain in marine low clouds. Part II: Heuristic models of rain formation. J. Atmos. Sci., 66, 2973-2990, https://doi.org/10.1175/2009JAS3072.1. C. S. Bretherton, D. Leon, A. D. Clarke, P. Zuidema, G. Allen, and H. Coe, 2011: An aircraft case study of the spatial transition from closed to open mesoscale cellular convection over the southeast Pacific. Atmos. Chem. Phys., 11, 2341-2370, https://doi.org/10.5194/acp-11-2341-2011.

—, D. Leon, M. Lebsock, J. Snider, and A. D. Clarke, 2012: Precipitation driving of droplet concentration variability in marine low clouds. J. Geophys. Res., 117, D19210, https://doi. org/10.1029/2012JD018305.

, and Coauthors, 2018: Ultraclean layers and optically thin clouds in the stratocumulus-to-cumulus transition. Part I: 
Observations. J. Atmos. Sci., 75, 1631-1652, https://doi.org/ 10.1175/JAS-D-17-0213.1.

Yang, Q., and Coauthors, 2012: Impact of natural and anthropogenic aerosols on stratocumulus and precipitation in the southeast Pacific: A regional modelling study using WRFChem. Atmos. Chem. Phys., 12, 8777-8796, https://doi.org/ 10.5194/acp-12-8777-2012.

Zhang, X., P. Massoli, P. K. Quinn, T. S. Bates, and C. D. Cappa, 2014: Hygroscopic growth of submicron and supermicron aerosols in the marine boundary layer. J. Geophys. Res. Atmos., 119, 8384-8399, https://doi.org/10.1002/2013JD021213.

Zheng, Y., D. Rosenfeld, and Z. Li, 2016: Quantifying cloud base updraft speeds of marine stratocumulus from cloud top radiative cooling. Geophys. Res. Lett., 43, 11 407-11413, https:// doi.org/10.1002/2016GL071185.

Zuidema, P., E. R. Westwater, C. Fairall, and D. Hazen, 2005: Ship-based liquid water path estimates in marine stratocumulus. J. Geophys. Res., 110, D20206, https://doi.org/10.1029/2005JD005833. 